\title{
Numerical and Experimental Study on the Hot Cross Wedge Rolling of Ti-6Al-4V Vehicle Lower Arm Preform
}

\section{Peiai Li}

University of Science and Technology Beijing

Baoyu Wang ( $\nabla$ bywang@ustb.edu.cn )

University of Science and Technology Beijing

Pengni Feng

University of Science and Technology Beijing

Jinxia Shen

University of Science and Technology Beijing

Jiapeng Wang

University of Science and Technology Beijing

\section{Research Article}

Keywords: Cross wedge rolling, TC4 alloy, Microstructure evolution, Mechanical properties, Lower arm preform

Posted Date: April 8th, 2021

DOl: https://doi.org/10.21203/rs.3.rs-384971/v1

License: (c) (1) This work is licensed under a Creative Commons Attribution 4.0 International License. Read Full License

Version of Record: A version of this preprint was published at The International Journal of Advanced Manufacturing Technology on October 12th, 2021. See the published version at https://doi.org/10.1007/s00170-021-07979-3. 


\title{
Numerical and Experimental Study on the Hot Cross Wedge Rolling of Ti-6AI-4V Vehicle Lower Arm Preform
}

\author{
Peiai Lia , Baoyu Wang ${ }^{\mathrm{a}, \mathrm{b} *}$, Pengni Feng ${ }^{\mathrm{a}}$, Jinxia Shen ${ }^{\mathrm{a}}$, Jiapeng Wang ${ }^{\mathrm{a}}$ \\ ${ }^{a}$ School of Mechanical Engineering, University of Science and Technology Beijing, Beijing \\ 100083, China \\ ${ }^{\mathrm{b}}$ Beijing Laboratory of Metallic Materials and Processing for Modern Transportation, Beijing \\ 100083, China \\ *Corresponding author: Baoyu Wang \\ E-mail address: bywang@ustb.edu.cn (Baoyu Wang), beibeipeipei@126.com (Peiai Li) \\ Tel.: +861082375671 \\ Fax.: +861062332923 \\ Postal address: No.30 Xueyuan Road, Haidian District, Beijing 100083, China
}

\begin{abstract}
Cross wedge rolling (CWR) has unique advantages in the production of shaft preforms with refined grains and improved mechanical properties. Considering the sensitivity of Ti-6Al-4V (TC4) alloy to heat treatment temperature, the effect of different initial deformation temperatures (IDTs) on the forming quality, mechanical properties and microstructure evolution of the TC4 alloy lower arm preforms in CWR forming were studied in this work. The flow stress curves of TC4 alloy in the two-phase region were obtained by isothermal compression experiments. The Arrhenius constitutive model was established and applied to DEFORM-3D finite element (FE) software to simulate the CWR forming process of TC4 alloy lower arm preforms. The forming quality of TC4 alloy parts was compared and analyzed by 3D FE simulation and experiment. And their mechanical properties at room temperature were tested by tensile test. The results showed that the rolled part has well forming quality (no steps and necking defects) and higher geometric dimension accuracy at the IDT $850^{\circ} \mathrm{C}$. Moreover, with the increase of IDT, the radial force and torque in the rolling process decrease. In addition, there were no internal defects in the parts rolled by different IDTs, because the die gap reduces the number of alternating cycles of tensile-compressive stress in the rolled workpieces. Compared with the initial state, the microstructure was refined. When the IDT is $885^{\circ} \mathrm{C}$, the ultimate tensile strength (UTS), yield strength (YS) and elongation (EI) of the parts were $987 \mathrm{MPa}$, $924 \mathrm{MPa}$ and $16.8 \%$ respectively, which was able to ensure the mechanical performance requirements of the lower arm preform. The results provide theoretical guidance for the actual production of lower arm preform by CWR.
\end{abstract}

Key words: Cross wedge rolling, TC4 alloy, Microstructure evolution, Mechanical properties, $\cdot$ Lower arm preform

\section{Introduction}

Wheeled armored vehicle plays an extremely important role in the modern battlefield, anti-terrorism, peacekeeping and other fields. The number of its equipment is also increasing according 
to strategic needs. The lower arm is the key component of wheeled armored vehicle suspension. Ti-6Al-4V (TC4) has the advantages of light weight, high strength, strong corrosion resistance, making it an ideal material in the aviation industry and military industry [1-3]. As the preferred material for the lower arm of wheeled armored vehicle, TC4 alloy not only contributes to reducing the weight of the vehicle, but also ensures that it can meet the requirements of service life under harsh road conditions. Most of the forging of lower arm preforms are produced by free forging and precision forging. Due to the large forging force, the free forging process is easy to form eccentricity, bending or crack when forging shaft parts. The precision forging process also has the disadvantage of expensive equipment and low production efficiency [4-6]. Cross wedge rolling (CWR) is a new near-net forming process, which can reduce the processing cost of shaft parts and improve their quality [7].

Steel products with good quality can be obtained by selecting suitable die parameters and process parameters during CWR $[8,9]$. It is necessary for us to further explore and research how to control the surface quality and internal quality of TC4 alloy shaft parts in the rolling process. Li et al. [10] investigated the effects of forming angle, the stretching angle and the area reduction on the spiral groove, internal defects and necking of the rolled workpiece by large number of CWR experiments. Zhou et al. [11] established a twice-stage CWR finite element model (FEM), and explained the necking law in detail. Pater et al. [12-14] used the method of combining experiment with 3D FE software Deform to systematically investigated various defects, temperature distribution, stress-strain distribution and rolling force change of workpiece during CWR. Maraghechi et al. [15] studied the central damage during CWR, and revealed the formation mechanism and development process of central damage by analyzing the central stress-strain state of rolled workpiece. Lee et al. [16] used the response surface method to optimize the CWR process parameters and obtained the process parameters to prevent the center hole defects of rolled workpiece. In addition, Studies have shown that the use of gaped die can significantly reduce the torsional deformation of the workpiece [17]. In the range of small area reduction $(\psi<55 \%)$, the use of gaped die was conducive to reducing the rolling force in the CWR process [18]. Pater et al. [19] studied the temperature and damage distribution in the process of CWR forming TC4 alloy drive shaft. The results showed that the damage factor reaches the maximum at the center section of the rolled workpiece. Çakırcalı et al. [20] revealed the generation and development of cracks in TC4 alloy workpiece during CWR process by FE simulation and experiments. However, the study by Huang et al. [21] showed that when the hollow shaft parts with different wall thicknesses were rolled by the gaped die in the CWR process, step defects with different heights appeared on the outer surface of the rolled workpiece. With the increase of ellipticity of hollow parts, the step defects were more obvious. He pointed out that this was caused by the elliptical deformation of the rolled workpiece in the rolling process. Ji et al. [22] studied the temperature distribution, force energy parameters and forming accuracy of the TC4 alloy blade preforms during the rolling process by CWR. Li et al. [23] studied the effects of die parameters and initial rolling temperature on the surface quality of TC4 alloy during CWR process.

The mechanical properties of titanium alloy are closely related to the microstructure characteristics, and the evolution of its microstructure will affect the flow behavior of the material [24]. TC4 alloy is sensitive to hot processing parameters. Different heat treatment conditions and deformation processing parameters can regulate the size, morphology and volume fraction of the phase. The equiaxed microstructure with an average grain size of $1.9 \mu \mathrm{m}$ was obtained by multi-directional isothermal forging (MDIF) of TC4 alloy by Zhang et al. [25], and the mechanism of grain refinement was studied. The tensile strength, yield strength and elongation of the alloy after grain refinement were 
greatly improved at room temperature and $400{ }^{\circ} \mathrm{C}$. Zhai et al. [26] studied the effects of $\alpha$ phase content and morphology on the microstructure and mechanical properties of TC4 alloy during multiple heat treatment processes by experimental method. Wang et al. [27] established the rate/temperature/microstructure constitutive model of TC4, and successfully predicted the evolution law of $\beta$-phase volume fraction and grain size during the process of hot ring rolling. Li et al. [28] studied the effects of IDT, area reduction and rolling speed on the volume fraction of $\alpha$ phase in TC6 alloy during CWR by FEM and experimental method. Therefore, it is necessary to study the corresponding law between the microstructure characteristics and mechanical properties of TC4 alloy during hot CWR.

The hot deformation behavior of TC4 alloy with bimodal microstructure was first studied by isothermal hot compression method, and the constitutive equation of TC4 alloy was established for FE simulation. Secondly, the thermodynamic coupling numerical simulation of CWR process of TC4 alloy lower arm preform was carried out by using software Deform, and the accuracy of FEMs were verified. Thirdly, the mechanism of forming steps and slight necking on the rolled workpiece surface under different IDTs were systematically analyzed. The internal quality of the rolled workpiece was tested and analyzed. Finally, the microstructure evolution and tensile mechanical properties at room temperature of parts were compared and analyzed.

\section{TC4 alloy material characteristic}

\subsection{Materials and experimental procedure}

Figure 1 shows the microstructure of initial TC4 alloy bar. The microstructure has globular primary $\alpha$ phase and lamellar secondary $\alpha$ phase. The chemical composition of the raw material used in this experiment is shown in Table 1.

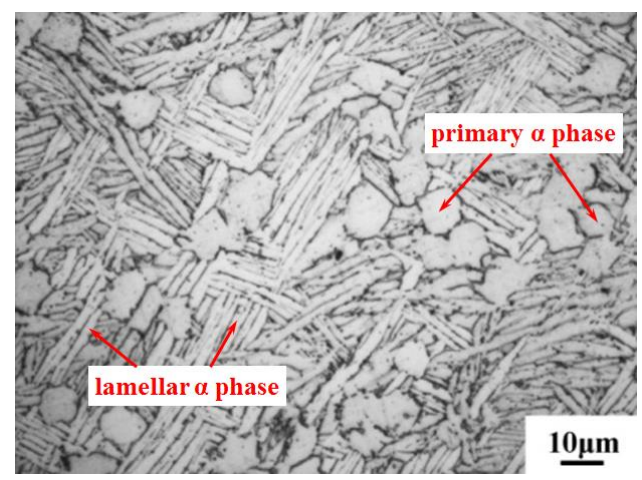

Fig. 1 Optical micrograph of received TC4 alloy

Table 1 Chemical composition of TC4 alloy (in $\mathrm{Wt} \%$ )

\begin{tabular}{cccccccc}
\hline \multicolumn{2}{l}{ Main chemical component } & \multicolumn{5}{c}{ Impurity content } \\
\hline $\mathrm{Ti}$ & $\mathrm{Al}$ & $\mathrm{V}$ & $\mathrm{Fe}$ & $\mathrm{C}$ & $\mathrm{N}$ & $\mathrm{H}$ & $\mathrm{O}$ \\
$\mathrm{Bal}$. & 6.14 & 4.15 & 0.18 & 0.011 & 0.008 & 0.002 & 0.16 \\
\hline
\end{tabular}

The Gleeble-1500D thermo-simulation machine was used to obtain isothermal compression data. The deformation temperatures and strain rates were set at $850^{\circ} \mathrm{C}, 900^{\circ} \mathrm{C}, 950^{\circ} \mathrm{C}$, and $0.1,1,10 \mathrm{~s}^{-1}$, respectively. After the test, the temperature of the specimen was immediately brought down to room temperature by water cooling. 


\subsection{Flow behavior}

The true stress-strain curves of the TC4 alloy at different strain rates and temperatures are shown in Fig. 2. The flow stress decrease with the increase of temperature, and differently, the flow stress increases with the increase of strain rate. The true stress-strain curves were all in the $\alpha+\beta$ two-phase field, and the stress increases rapidly to a peak at low strain and then decreases to the steady state, which were more prominent at higher temperatures and lower strain rates. At relatively low strain rates, dynamic recovery or dynamic recrystallization causes softening of the material flow and a significant decrease in stress value [29]. In high strain rate conditions, the flow softening and work hardening reach a balanced state, and then the flow stress-strain curve tends to be stable.
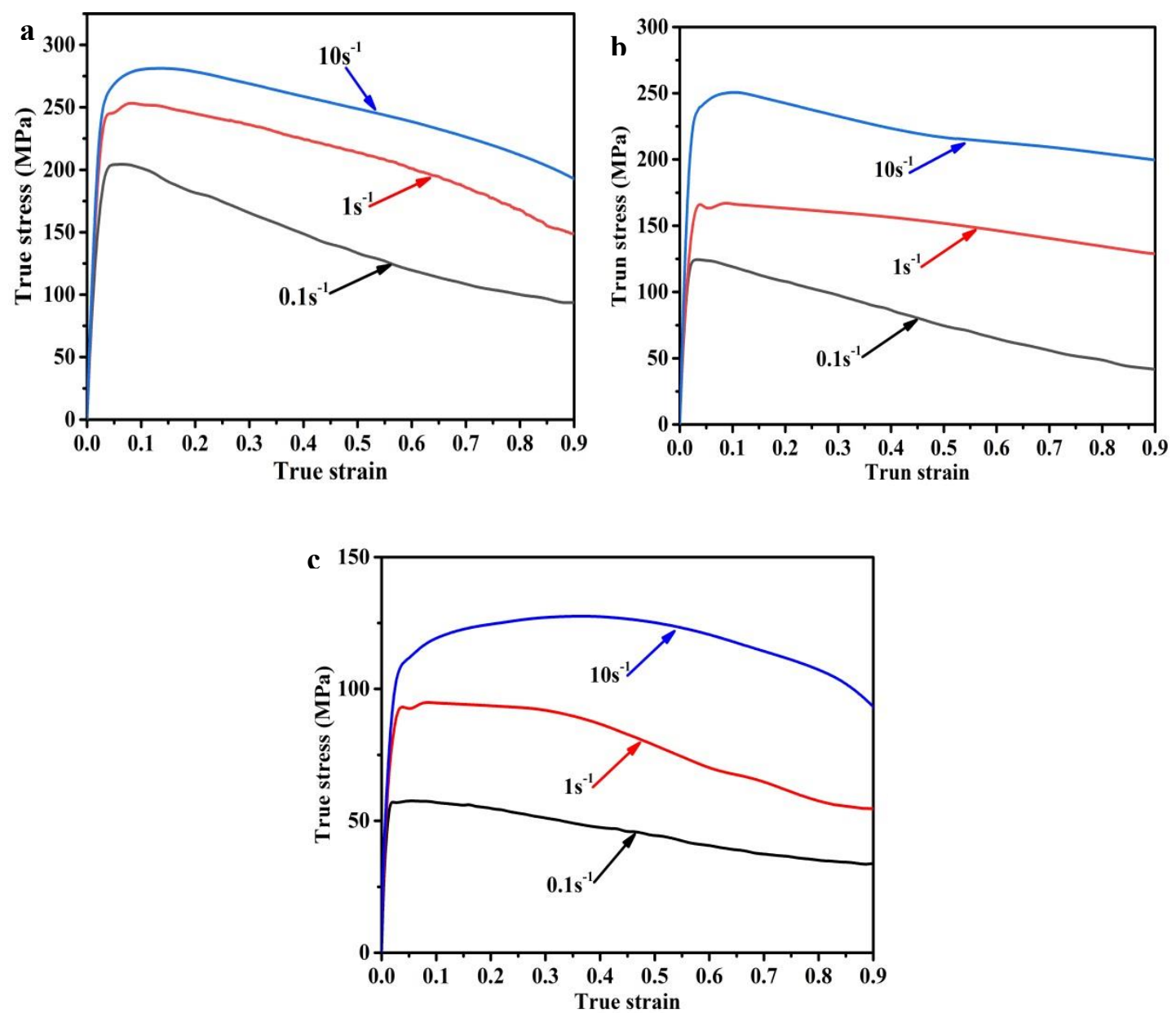

Fig. 2 True stress-strain curves of TC 4 alloy: a $850{ }^{\circ} \mathrm{C}, \mathbf{b} 900^{\circ} \mathrm{C}, \mathbf{c} 950{ }^{\circ} \mathrm{C}$

\subsection{Determination of material constants}

The Arrhenius equation can accurately describe the constitutive equation of TC4 alloy at high temperatures $[22,23]$. The material constants can be determined separately according to the isothermal compression test data at different strain rates and temperatures. It is expressed as follows:

$$
\&=A[\sinh (\alpha \sigma)]^{n} \exp \left(-\frac{Q}{R T}\right)
$$

where $Q\left(J \cdot \mathrm{mol}^{-1}\right)$ is the activation energy, $R$ is the gas constant of $8.3145\left(\mathrm{~J} \bullet \mathrm{mol}^{-1} \bullet \mathrm{K}^{-1}\right), \& \&$ is the strain rate, $T$ is the absolute temperature $(K)$, while $A, \alpha$ and $n$ are the constants.

The $\&$ parameters for TC4 alloy can be described by following: 


$$
\&=1.3678 \times 10^{40}[\sinh (0.0061 \sigma)]^{6.1302} \exp \left(-\frac{914135}{R T}\right)
$$

The correlation coefficient $(R R)$ and average absolute relative error $(A A R E)$ were used to evaluate the accuracy of the equation, as follows:

$$
\begin{gathered}
R R=\frac{\sum_{i=1}^{N}\left(X_{i}-\bar{X}\right)\left(Y_{i}-\bar{Y}\right)}{\sqrt{\sum_{i=1}^{N}\left(X_{i}-\bar{X}\right)^{2}} \sqrt{\sum_{i=1}^{N}\left(Y_{i}-\bar{Y}\right)^{2}}} \\
A A R E=\frac{1}{N} \sum_{i=1}^{N}\left|\frac{Y_{i}-X_{i}}{Y_{i}}\right| \times 100 \%
\end{gathered}
$$

In the equations, $X_{i}$ and $Y_{i}$ are the predicted and experimental peak stress, $\bar{X}$ and $\bar{Y}$ are the average predicted and experimental peak stress, $N$ is the number of peak stresses. Fig. 3 shows the comparison between the predicted and experimental peak stress. RR and AARE are 0.9737 and $8.4342 \%$, indicating that the constitutive equation of TC4 alloy established in this paper has high credibility.

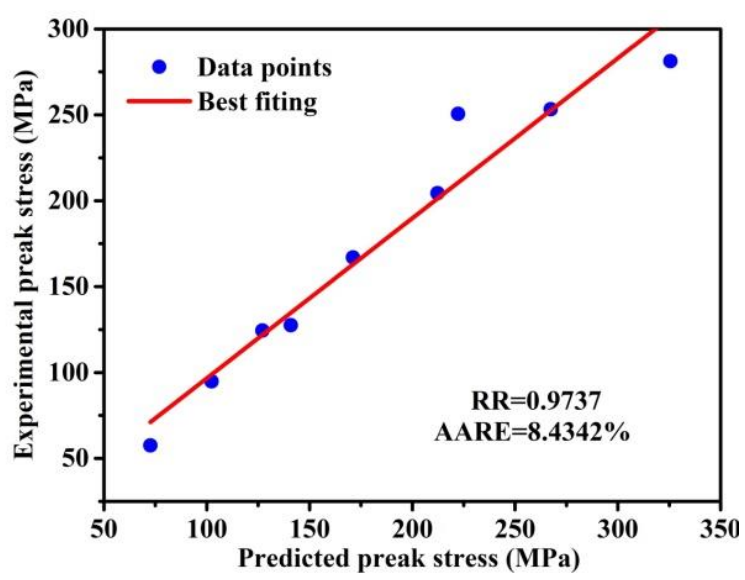

Fig. 3 Comparison of predicted peak stress and experimental peak stress

\section{Finite element simulation and experiment}

\subsection{Finite element simulation}

The FEM for the CWR study is shown in Fig. 4. As the geometrical model of the test specimens and the rolling dies were symmetrical, the boundary conditions of the FEM were set to be symmetrical relative to the center plane. The following assumptions were made in the course of this study. (1) Because the deformation can be ignored, the roll dies and guide plates considered as rigid bodies. (2) The workpiece regarded as a plastic body. (3) The coefficient of friction between workpiece and tool contact surfaces was assumed to be constant. The shear friction model was used for the type of friction: $f_{\mathrm{s}}=m \times k$, where $f_{\mathrm{s}}, k$ and $m$ are the friction force, shear yield stress and the coefficient of friction, respectively. (4) The heat transfer coefficient between the workpiece and the environment, the dies are listed in detail in Table 2. 


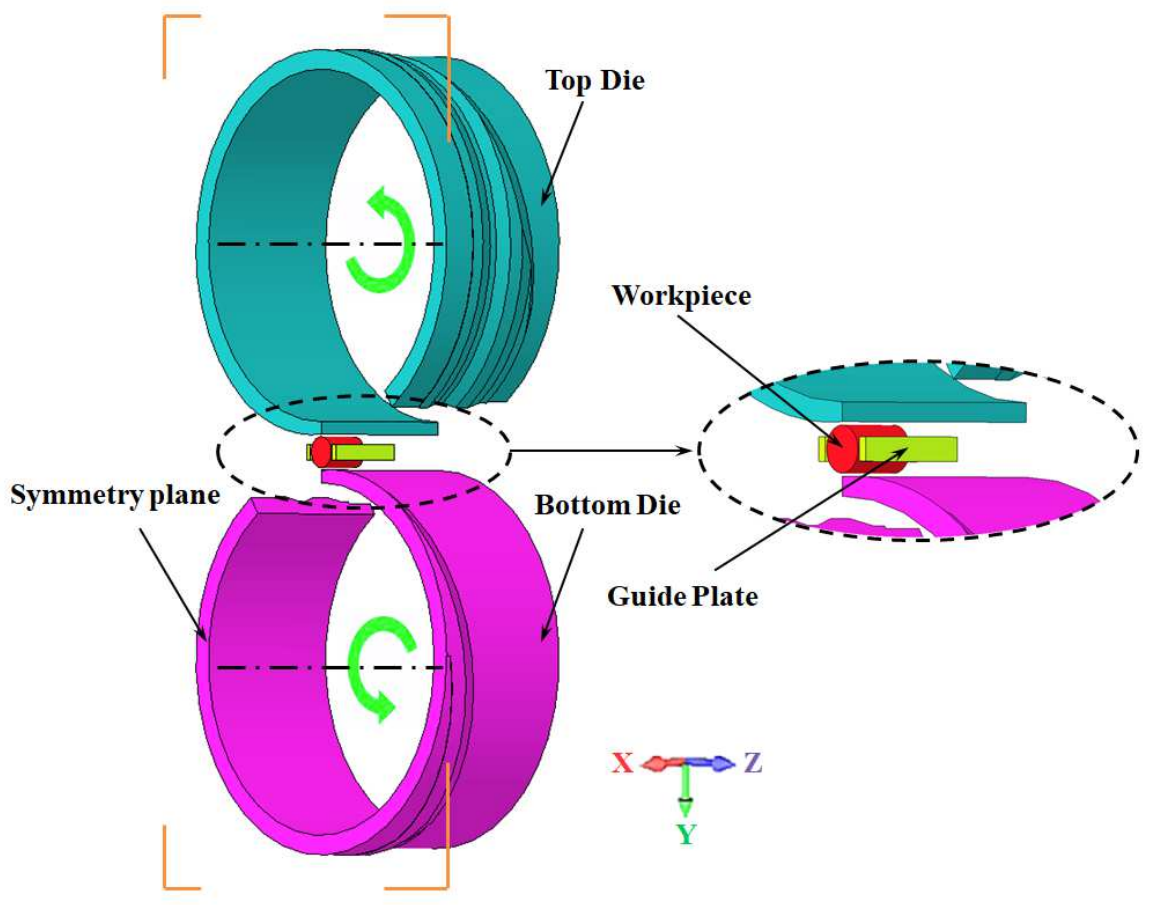

Fig. 4 FEM of CWR for TC4 alloy

The parameters of the plane layout of a CWR die are shown in Fig. 5. Only the wedge, stretching and sizing zone in the middle of the dies were used. The surface of the dies was machined with a gap of $1 \mathrm{~mm}$ in depth. TC4 alloy parts with an area reduction of $48 \%$. The main technical parameters are shown in Table 2.

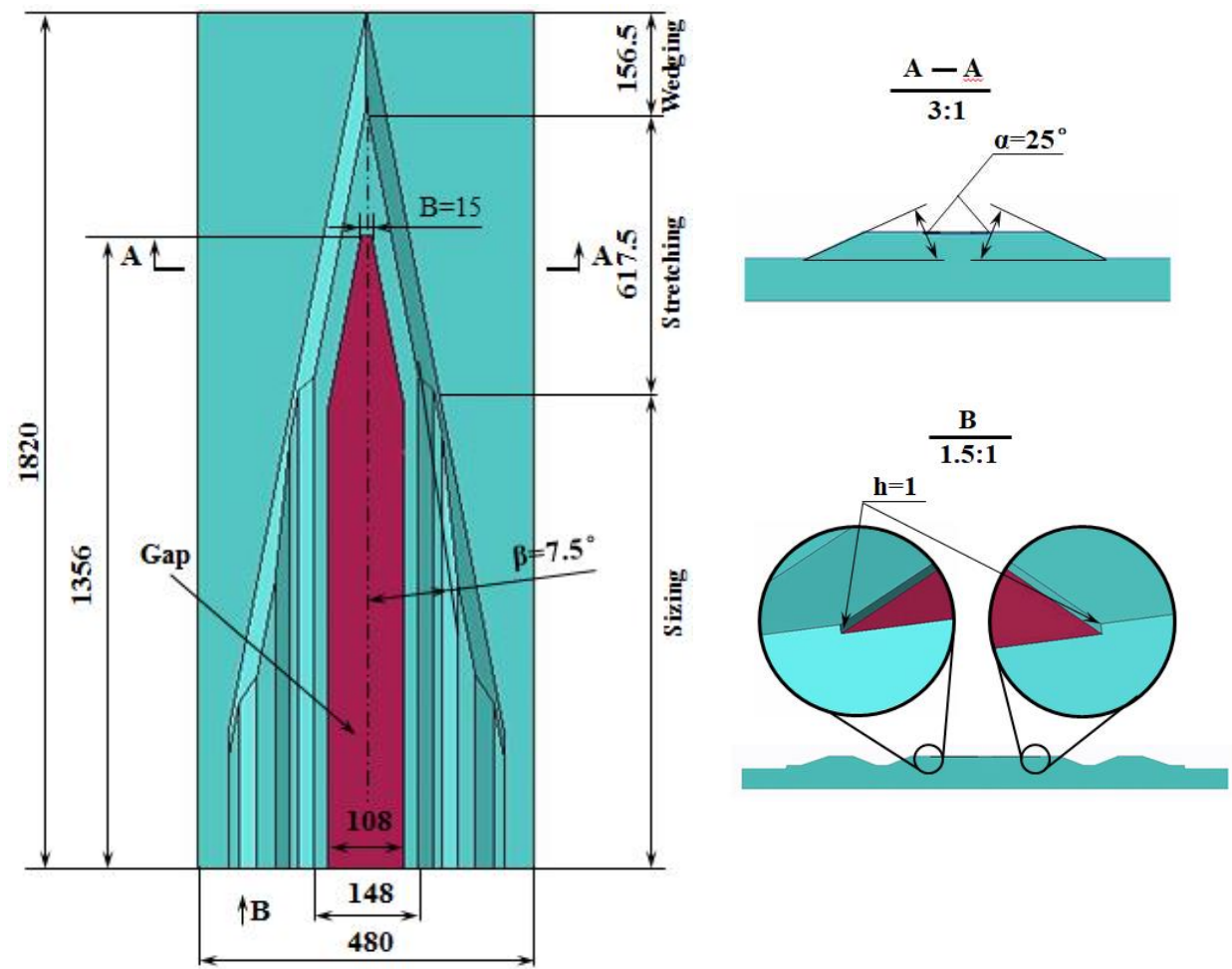

Fig. 5 Forming wedge tool parameters for H630 rolling mill 


\begin{tabular}{lc}
\hline Parameters & Value \\
\hline Heat transfer coefficient $\left(\mathrm{Wm}^{-2} \mathrm{~K}^{-1}\right)$ & $11 \times 10^{3}$ \\
Convection coefficient $\left(\mathrm{Wm}^{-2} \mathrm{~K}^{-1}\right)$ & 20 \\
Thermal conductivity $\left(\mathrm{KWm}{ }^{-2} \mathrm{~K}^{-1}\right)$ & 17 \\
Coefficient of mechanical energy to heating & 0.9 \\
Temperature of tools $\left({ }^{\circ} \mathrm{C}\right)$ & 20 \\
Friction factor between workpiece and plate & 0.1 \\
Friction factor between workpiece and die & 0.9 \\
Environment temperature $\left({ }^{\circ} \mathrm{C}\right)$ & 20 \\
Speed of roll $(\mathrm{rpm})$ & 8 \\
\hline
\end{tabular}

\subsection{Cross-wedge rolling experiment}

The H630 CWR mill of Beijing University of Science and Technology was used for experiments. The experimental equipment is shown in Fig. 6a and the forming wedge dies are shown in Fig. 6b. Depending on the recrystallization temperature and $\beta$-phase transus temperature of TC4 alloy, four different IDTs were selected: $855^{\circ} \mathrm{C}, 885{ }^{\circ} \mathrm{C}, 915{ }^{\circ} \mathrm{C}$ and $945{ }^{\circ} \mathrm{C}$. Before the experiment, the workpiece was heated in a tubular furnace and hold for 50 minutes. Shorten the transfer time between tube furnace and mill to reduce temperature loss. Water cooling was adopted after rolling.
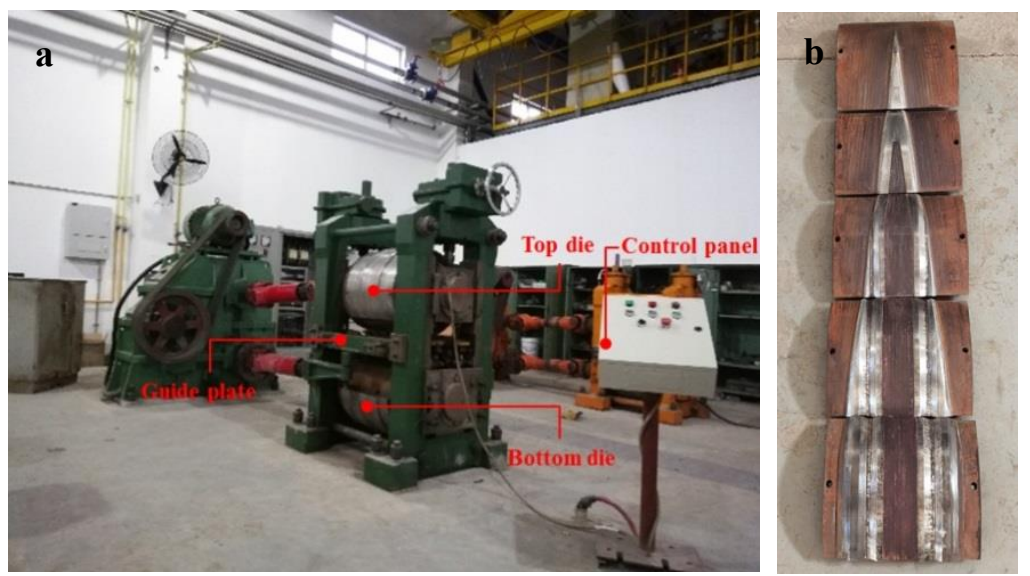

Fig. 6 Experimental equipment and manufactured die: a H630 mill, b Forming wedge dies

\subsection{Microstructure and mechanical properties experiments}

The parts were cut into symmetrical sections along the axial direction and in the mirror plane position respectively after rolling. The microstructure and internal quality of TC4 alloy parts were observed by cutting samples in the core of the complete forming zone.

The microstructure was observed by optical microscope (OM) at room temperature. Preparation of OM specimens includes mechanical grinding with sandpaper of different fineness, electrolytic polishing with 5\% alcohol perchlorate solution and chemical etching with Kroll's solution. Image Pro-plus software was used to quantitatively measure the value of primary $\alpha$ phase. The tensile test at room temperature according to GB/T228.1-2010.

\section{Results and discussion}

\subsection{Verification of the CWR FEM}

Figure 7 shows the appearance of TC4 alloy parts. The part at the IDT of $855{ }^{\circ} \mathrm{C}$ shows necking in the middle, while the part at $885{ }^{\circ} \mathrm{C}$ has a smooth outer surface with no folding, no 
spiral mark and crack. However, the central of the parts at the IDT of $915{ }^{\circ} \mathrm{C}$ and $945^{\circ} \mathrm{C}$ showed obvious steps and slight spiral marks.

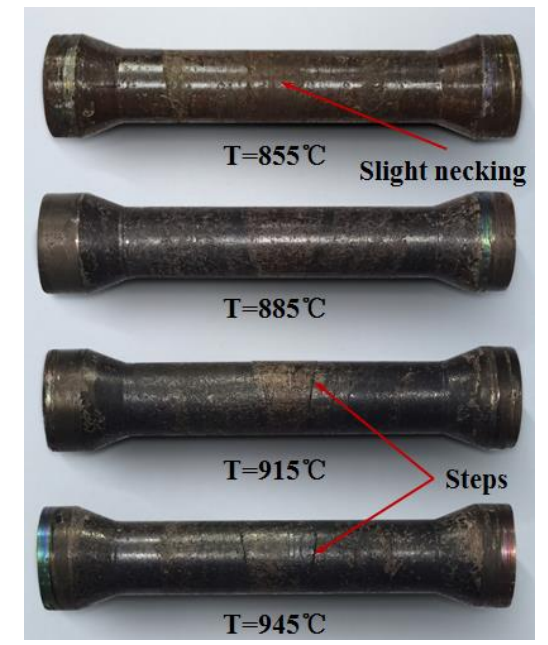

Fig. 7 The parts of rolled

Geomagic Qualify software was used to compare the geometric dimensions of FEM and high-precision 3D scanning parts. As shown in Fig. 8a to d, the radial differences of the maximum and minimum diameters of the parts corresponding to the four simulation results are distributed in the range of $1.002 \sim 1.115 \mathrm{~mm}$ and $-1.002 \sim-1.115 \mathrm{~mm}$, respectively. The geometrical dimensions difference between the simulation results and the experimental samples is small. This shows that it is reliable to simulate the CWR forming process of TC4 alloy by FEM.
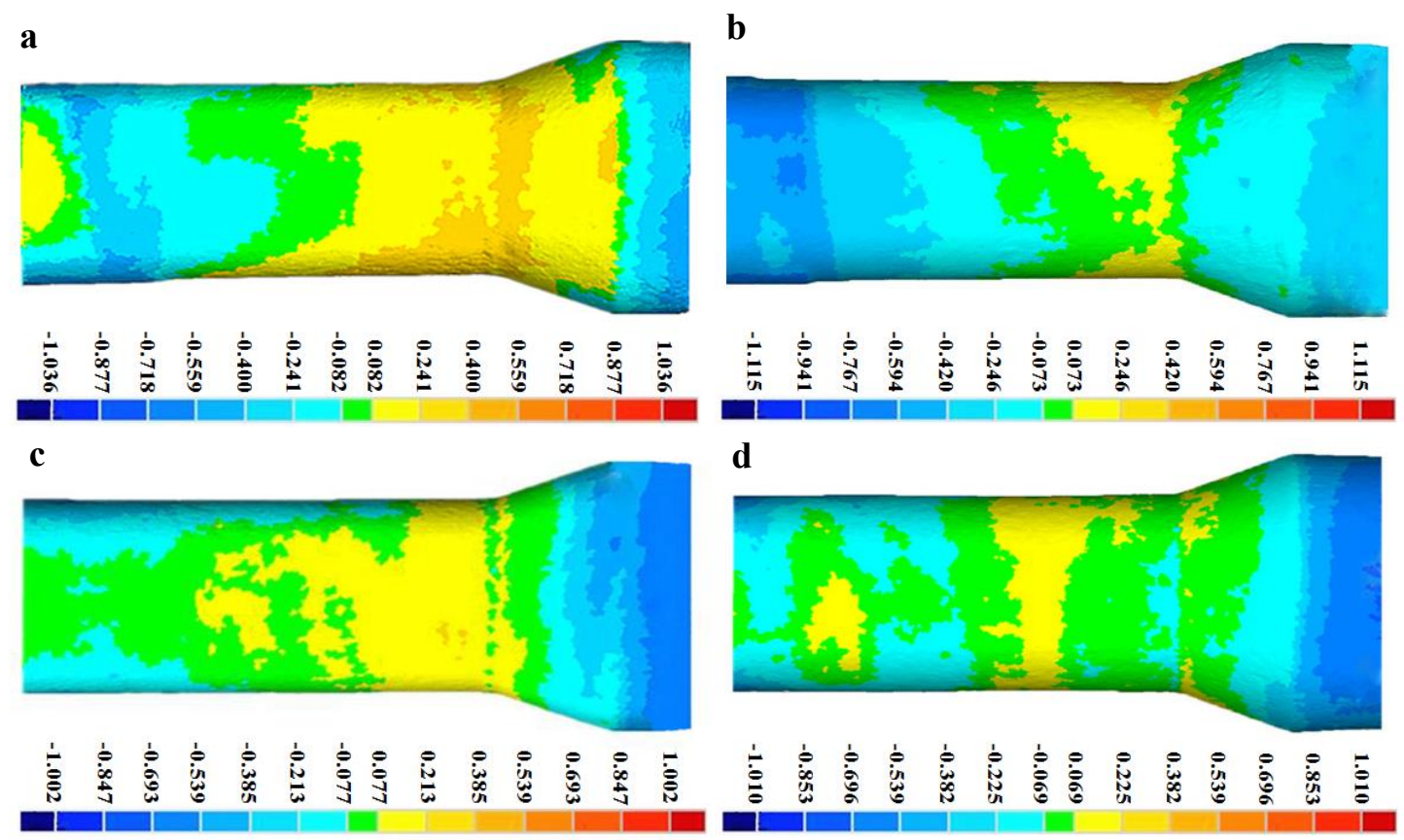

Fig. 8 Comparison of TC4 Alloy CWR Parts and simulated results: a IDT at $945^{\circ} \mathrm{C}$, b IDT at $915^{\circ} \mathrm{C}, \mathbf{c}$ IDT at $885^{\circ} \mathrm{C}, \mathbf{d}$ IDT at $855^{\circ} \mathrm{C}$

\subsection{Non-roundness analysis}

The CWR and step forming process of the TC4 alloy lower arm are shown in Fig. 9. When the workpieces with IDT of $915^{\circ} \mathrm{C}$ and $945^{\circ} \mathrm{C}$ entered the stretching zone for a short time, steps appeared on their surface. After rolling, the steps were still retained. The generation of steps not only reduces the 

process, causing serious harm to the performance of the lower arm, which should be avoided.

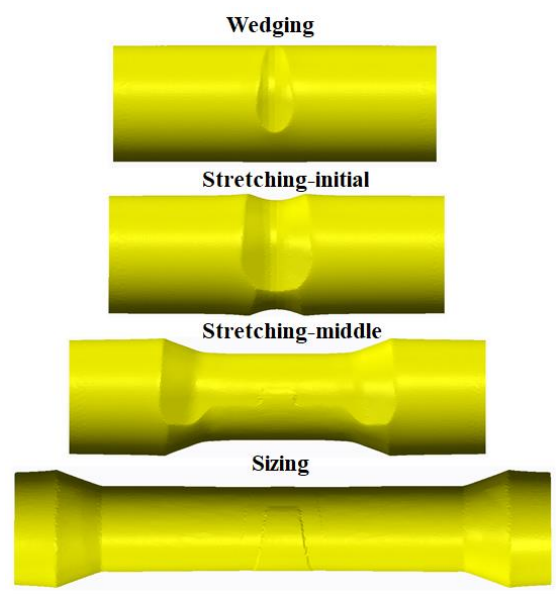

Fig. 9 Different stages of CWR and step forming

As can be seen from Fig. 10 and 11, before entering the gap area (before $t=1.84 \mathrm{~s}$ ), the material was gradually compressed along the axial direction by the dies. The symmetrical section of the workpiece with IDT of $945{ }^{\circ} \mathrm{C}$ was still elliptical, while the symmetry section of the rolled workpiece at $880^{\circ} \mathrm{C}$ was circular, and the diameter was consistent with the die surface spacing. After $\mathrm{t}$ $=1.84 \mathrm{~s}$, the rolled workpiece entered the gap area. The maximum diameter of the symmetrical section of the rolled workpiece with IDT of $945^{\circ} \mathrm{C}$ was larger than the distance between the surfaces of the top and bottom dies gap area. Therefore, the material was extruded into the cavity due to the oval deformation during rolling. The workpiece with IDT of $885{ }^{\circ} \mathrm{C}$ had no material squeezed into the cavity of the gap area, and no step was formed on the surface of the rolled workpiece. The material deformation resistance is low at the high temperature, and the tangential material flow tends to increase, resulting in more serious oval deformation during rolling, which eventually leads to the formation of steps at high temperature
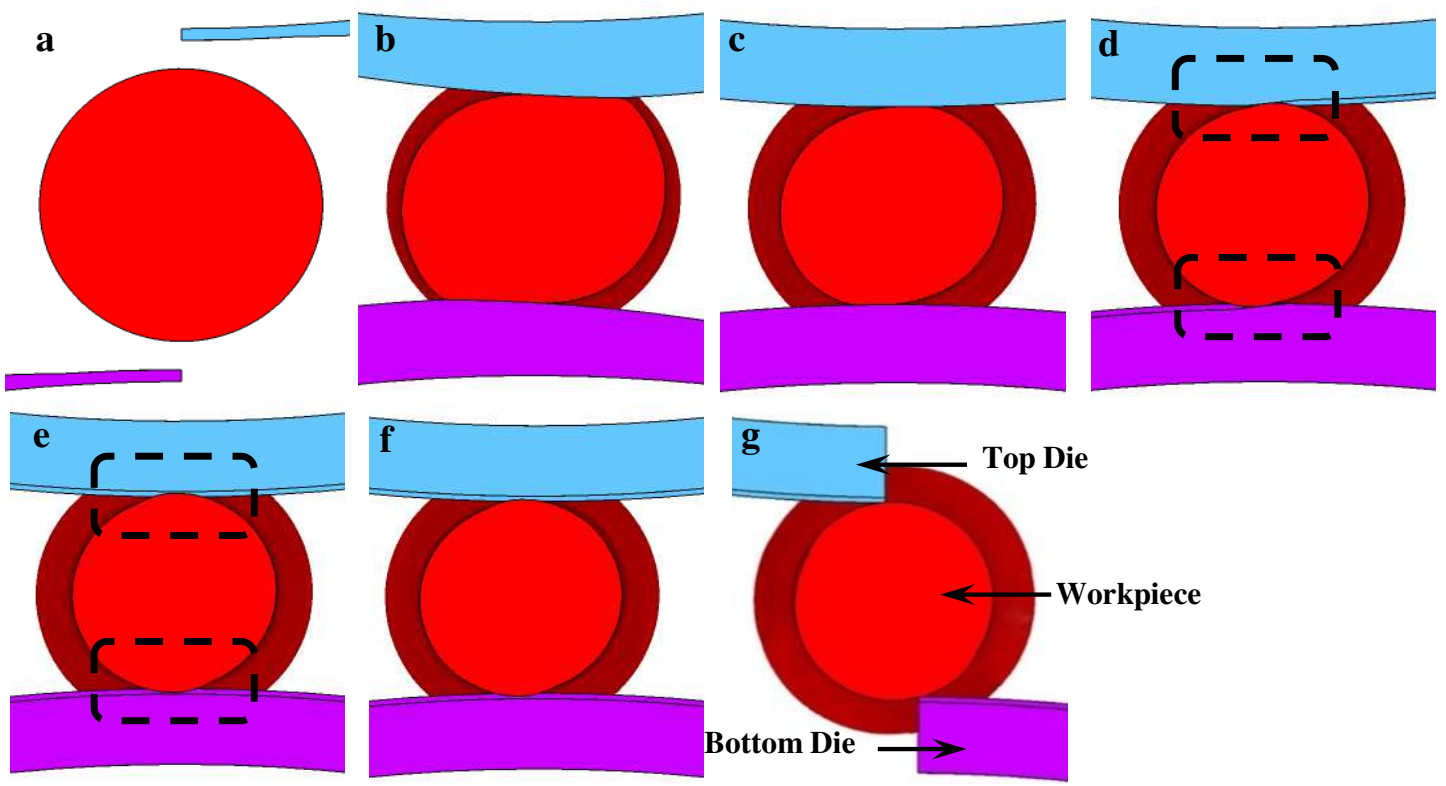

Fig. 10 Cross-section profile during forming process at IDT of $945^{\circ} \mathrm{C}$ : a initial status $\mathrm{t}=0 \mathrm{~s}, \mathbf{b}$ wedging stage $\mathrm{t}=0.8 \mathrm{~s}, \mathbf{c}$ stretching stage $\mathrm{t}=1.52 \mathrm{~s}, \mathbf{d}$ preparing for the gap stage $\mathrm{t}=1.84 \mathrm{~s}$, $\mathbf{e}$ gap stage $\mathrm{t}=2.4 \mathrm{~s}, \mathbf{f}$ sizing stage $\mathrm{t}=3.2 \mathrm{~s}, \mathbf{g}$ completion status $\mathrm{t}=5.64 \mathrm{~s}$ 

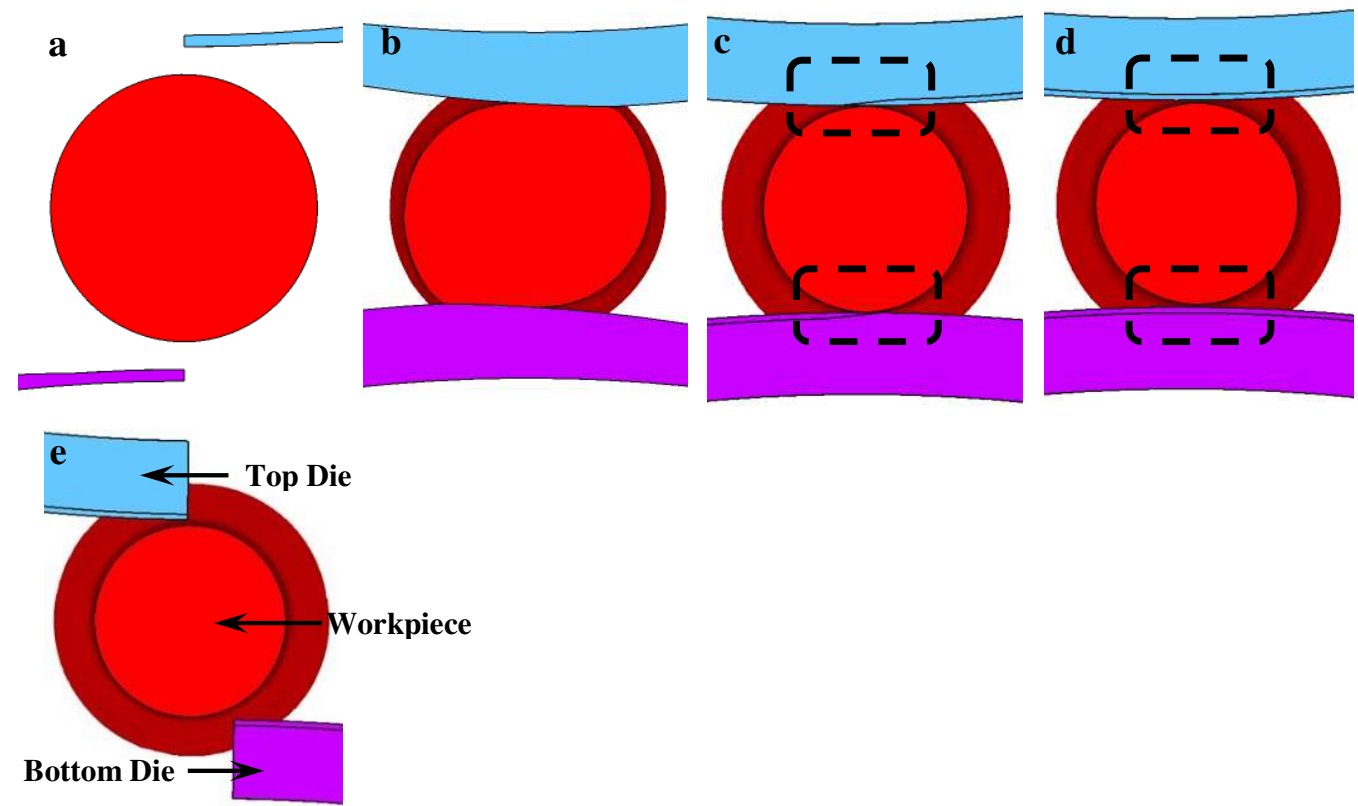

Fig. 11 Cross-section profile during forming process at IDT of $885^{\circ} \mathrm{C}$ : $\mathbf{a}$ initial status $\mathrm{t}=0 \mathrm{~s}, \mathbf{b}$ wedging stage $\mathrm{t}=0.8 \mathrm{~s}, \mathbf{c}$ preparing for the gap stage $\mathrm{t}=1.84 \mathrm{~s}, \mathbf{d}$ sizing stage $\mathrm{t}=3.2 \mathrm{~s}$, e completion

$$
\text { status } \mathrm{t}=5.64 \mathrm{~s}
$$

In Fig. 12a-b, the periodic contacts between the workpiece and the surface of die gap area during rolling were recorded by smearing pink paint evenly on the surface of the die gap area. This is because the rolled workpiece before entering the gap area did not form a standard circular section but form an oval section with a larger size. The oval cross-section contacts with the surface of the roll cavity, and the contact scratches can be recorded after rolling.

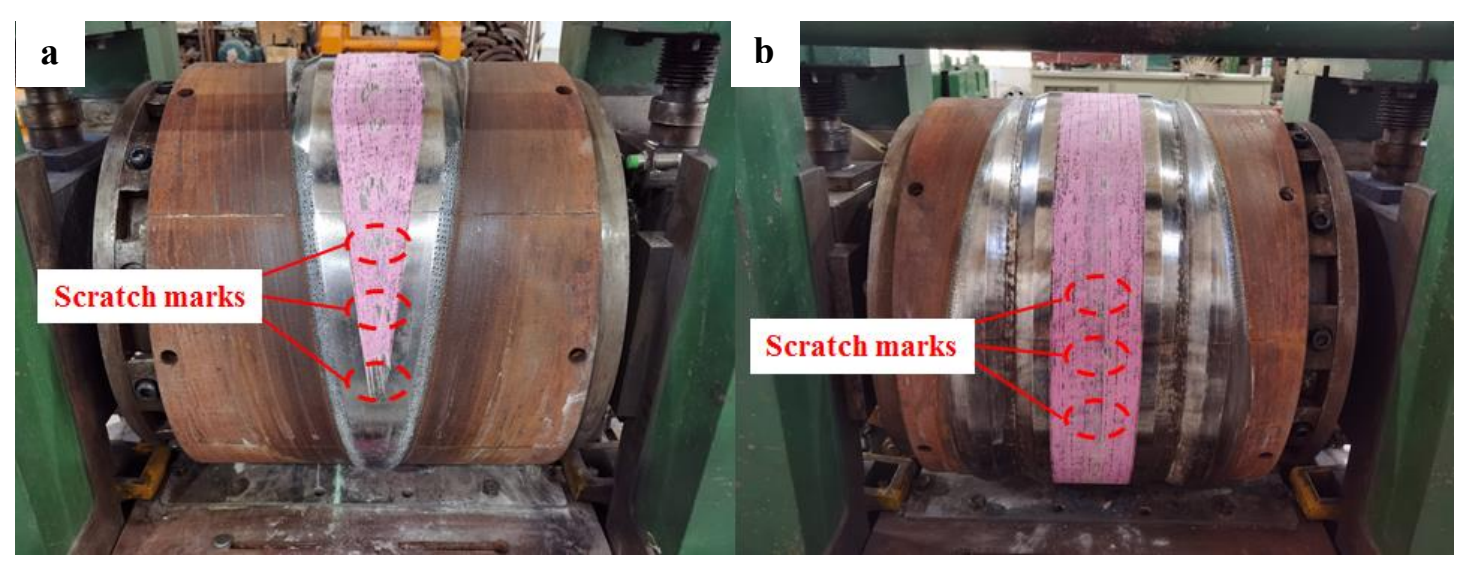

Fig. 12 The distribution of scratch marks on the surface of the die gap area: a scratch marks in stretching zone, b scratch marks in sizing zone

To study the variation of different cross-sectional shapes in the forming area of parts, a non-circularity index should be defined [21]. The following formula (5) was used to calculate the non-circularity:

$$
e=\frac{2\left(D_{\max }-D_{\min }\right)}{D_{\max }+D_{\min }}
$$
represents the non-circularity. 
In Fig. 13, the rolled workpiece of FEM with IDT of $945^{\circ} \mathrm{C}$ matches well with the outer surface shape of the experiment. The projection contour curves of 15 equidistant cross-sections along the axis direction of the experimental parts were selected to analyze the dimensions of the parts after forming.

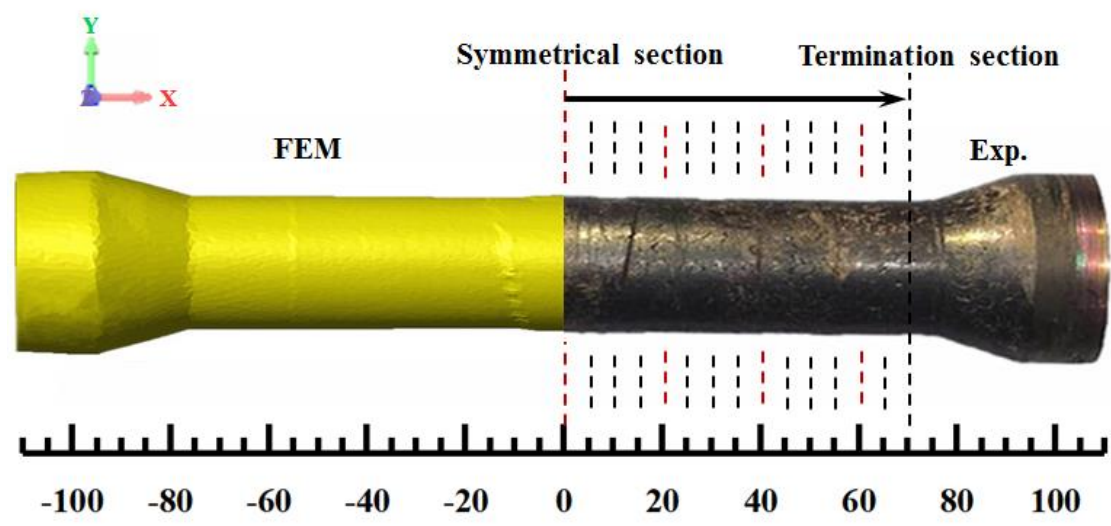

Fig. 13 Cross-section distribution position

Figure 14a shows the influence of IDT on the non-circularity of symmetrical sections. The non-circularity of the symmetrical section increases with the increase of the IDT. The lower the IDT is, the shorter the time for the non-circularity of the outer surface at the symmetrical section of the part to reach a stable value. This may be because the rolled workpiece with low IDT first reached the temperature range that is not easy to deform, which weakens the flow performance of the material. In Fig. 14b, the non-circularity value at the symmetric section position reaches the maximum, and decreases gradually along the axial direction on both sides. The reason is that at the beginning of the rolling stage, the volume of the material without deformation is relatively large. The material in the deformed zone is subjected to relatively large resistance to flow in the axial direction, which weaken the material axial flow. The material in deformation area only expands along the radial direction, so that the non-circularity is relatively large. In the subsequent rolling process, the volume of material without deformation decreases gradually, and the resistance to the flow of material along the axial direction decreases, which is relatively easy to be driven. Thus, the distribution law of the non-circularity value is obtained, which is the largest in the symmetric section and decreases gradually along the axial direction.
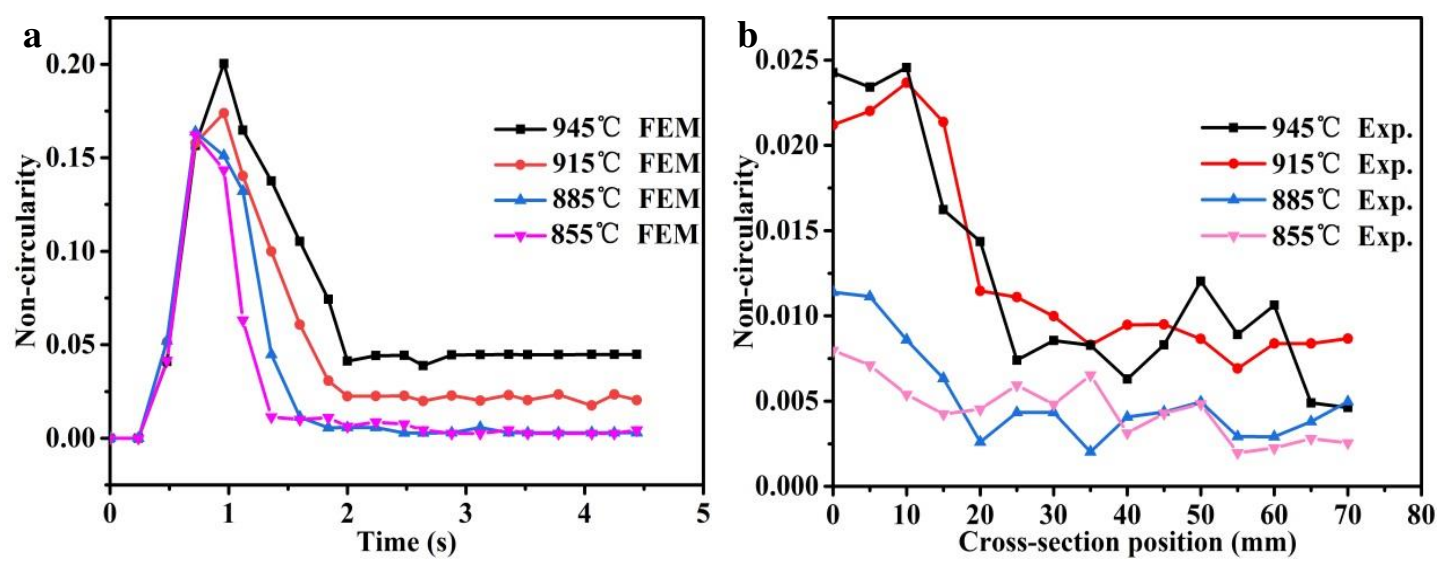

Fig. 14 Non-circularity value of outer surface of parts at different IDT: a non-circularity results of symmetric section of FEM during rolling, $\mathbf{b}$ non-circularity results of experiments at different axial position

\subsection{Stress and strain analysis}

This paper further analyzes the formation mechanism of non-circularity by studying the evolution 
of stress and strain distribution of workpieces at different IDTs. Fig. 15 shows the stress distribution of the symmetrical section of the workpiece at $1.84 \mathrm{~s}$. Under the IDT of $945{ }^{\circ} \mathrm{C}$ and $915{ }^{\circ} \mathrm{C}$, the symmetrical sections of the workpieces are elliptical to varying degrees. Radial stress (Stress-R) and circumferential stress (Stress-Theta) have obvious orthogonal distribution. The radial stress is tensile stress along the long-axis direction of the elliptical section and compressive stress along the short-axis direction. The distribution of circumferential stress is exactly opposite to the radial stress. With the decrease of IDT, the tensile and compressive stress distribution of radial stress tends to be uniform. The circumferential compressive stress transfers to the center of the section, and its distribution also tends to be uniform. The axial stress (Stress-Z) at the center of the cross-section at different IDTs is shown as tensile stress. In the process of IDT decreasing from $945{ }^{\circ} \mathrm{C}$ to $855^{\circ} \mathrm{C}$, the axial tensile stress range gradually expands from the central region to the outer surface. Finally, the axial stress of the section is all tensile stress.

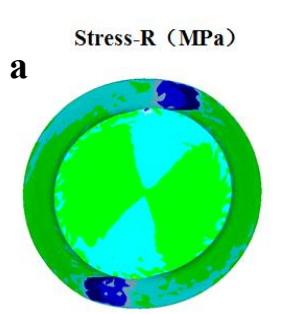

Stress-R (MPa)

b

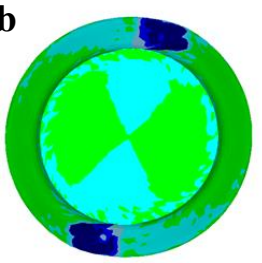

Stress-R（MPa）

c

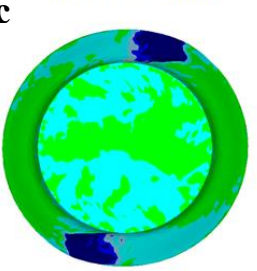

d Stress-R (MPa)

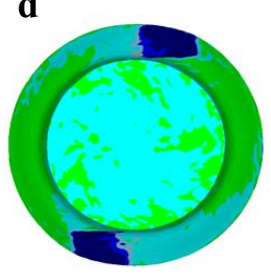

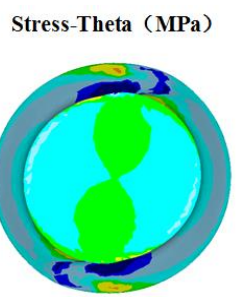

Stress-Theta (MPa)

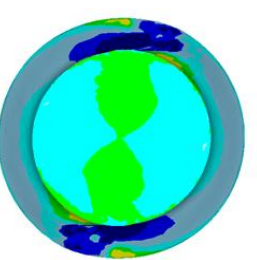

Stress-Theta (MPa)

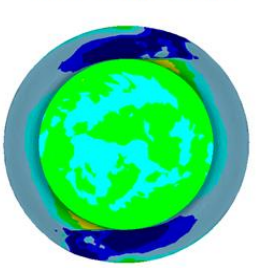

Stress-Theta (MPa)

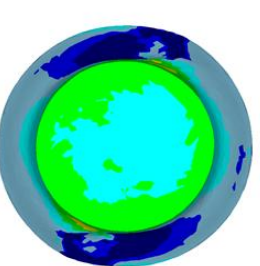

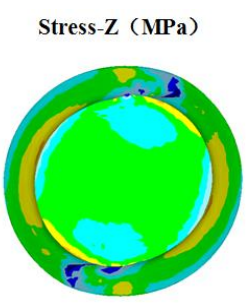

Stress-Z (MPa)

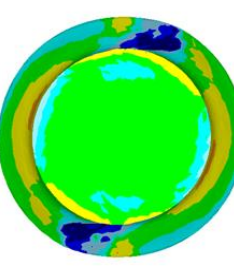

Stress-Z (MPa)

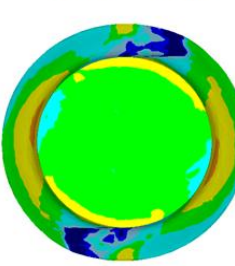

Stress-Z (MPa)

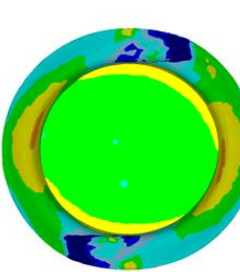

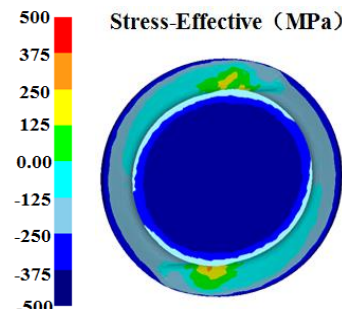
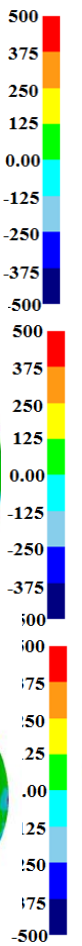

Stress-Effective (MPa)
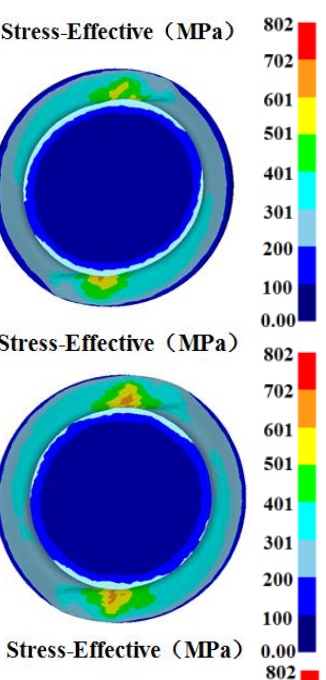

Stress-Effective (MPa)

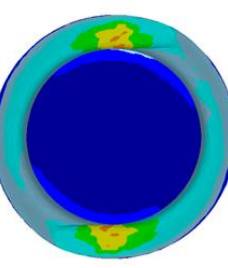

Stress-Effective (MPa)

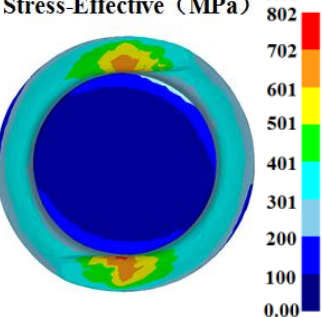

Fig. 15 Stress distribution in the stretching zone: a $\mathrm{T}=945^{\circ} \mathrm{C}, \mathbf{b} \mathrm{T}=915^{\circ} \mathrm{C}, \mathbf{c} \mathrm{T}=885^{\circ} \mathrm{C}, \mathbf{d}$

$$
\mathrm{T}=855^{\circ} \mathrm{C}
$$

Figure 16 shows the strain distribution of the symmetrical section of the workpiece at $1.84 \mathrm{~s}$ at different IDTs. The radial strain (strain-R) gradually decreases from the outer surface to the center. When the IDT at $945{ }^{\circ} \mathrm{C}$, due to the compressive stress, the distribution of compressive strain along the long-axis in the central region is wider than that along the short-axis, and the distribution of compressive strain near the outer surface is opposite to that in the central region. It can be observed in the circumferential strain (Strain-theta) distribution that the compressive strain is all along the long-axis 
direction, and a circular tensile strain band appears on both sides of the long-axis near the outer surface. The axial strain (Strain-Z) distribution has no significant change. The workpiece material flows to the intersection area of the long-axis and the outer surface under the combined action of the above strain, and the ovality is more obvious than other IDT conditions. As the IDT decreases, the radial strain annulus area near the outer surface gradually becomes homogeneous, and the tendency of the material flowing from the outer surface to the center tends to be the same everywhere. When the IDT decreases to $885{ }^{\circ} \mathrm{C}$, the circumferential tensile strain gradually disappears and the circumferential compressive strain dominates the distribution. A uniform compressive strain ring is formed on the surface layer, which enables the surface material to flow uniformly along the circumferential direction, and the ovality of the section decreases. With the further decrease of IDT, the axial tensile strain value increases, the radial compressive strain region and the compressive strain value also increase, and a necking trend appears in the middle of the workpiece.

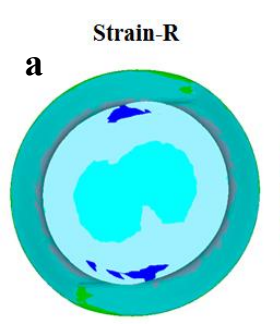

b Strain-R
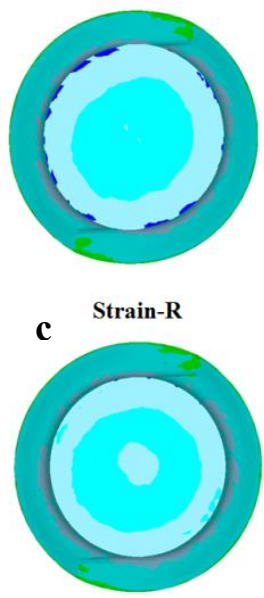

d

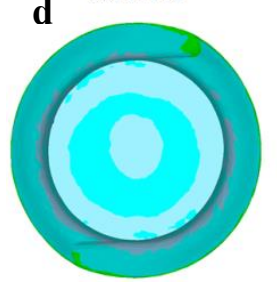

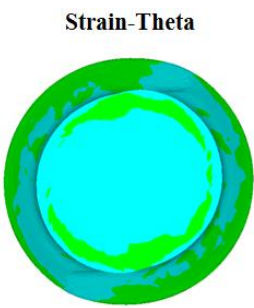

Strain-Theta

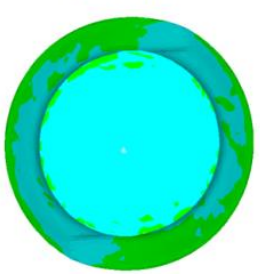

Strain-Theta

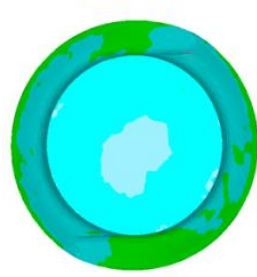

Strain-Theta

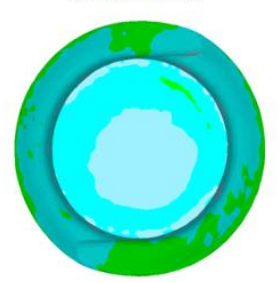

Strain-Z

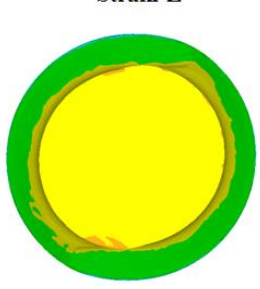

Strain-Z

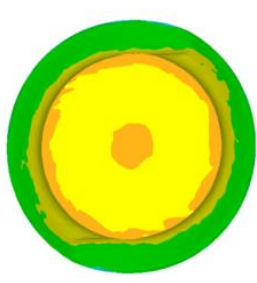

Strain-Z

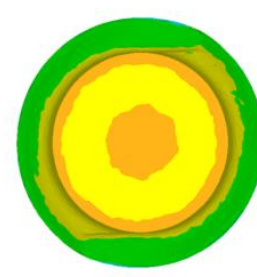

Strain-Z

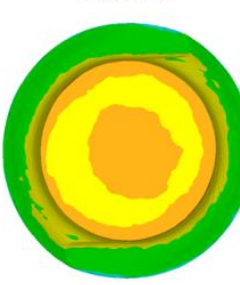

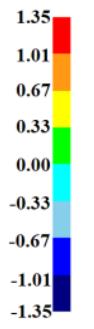
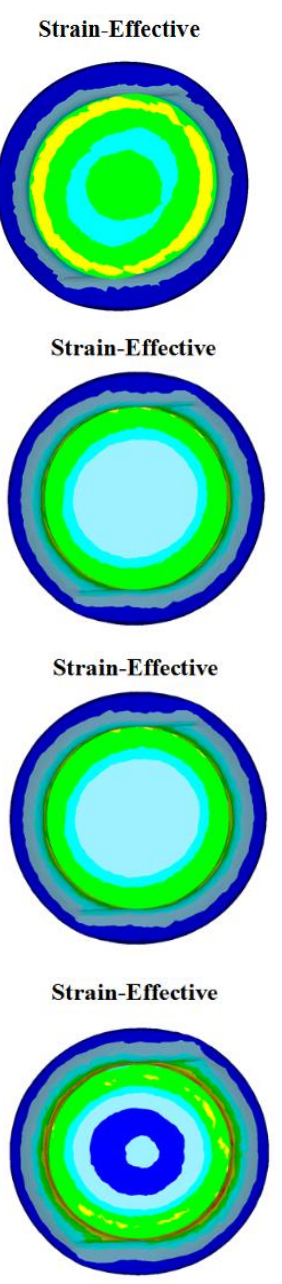

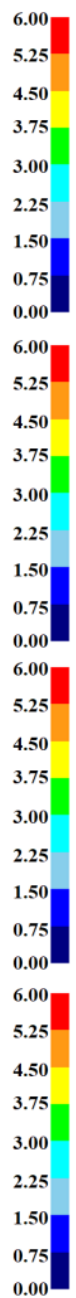

Fig. 16 Strain distribution in the stretching zone: a $\mathrm{T}=945^{\circ} \mathrm{C}, \mathbf{b} \mathrm{T}=915^{\circ} \mathrm{C}, \mathbf{c} \mathrm{T}=885^{\circ} \mathrm{C}, \mathbf{d ~ T}=$ $855^{\circ} \mathrm{C}$

\subsection{Analysis of the Force Energy Parameters}

The force condition of the workpiece is particularly complex in the CWR process. Large plastic deformation often occurs along the axis and diameter direction of the workpiece. In order to achieve large plastic deformation, the mill needs to be able to provide sufficient rolling force and torsional moment. This is an important basis for the design of the mill and the selection of the appropriate motor power [30]. Therefore, it is essential to analyze the radial force and torque 
corresponding to the different moments in the forming process. The radial force and torque during the FE simulation of CWR are shown in full in Fig. 17.
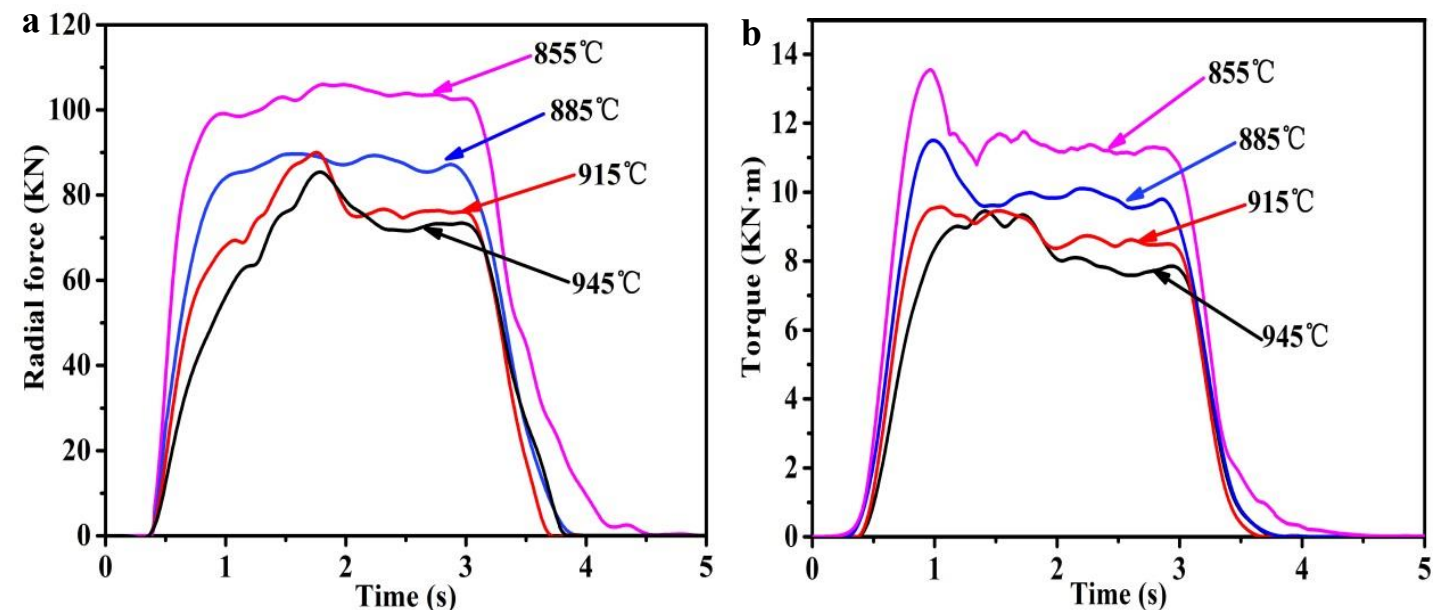

Fig. 17 Effective of the IDTs on force and torque in CWR processes

The steady radial force and torque gradually increase with the decrease of IDT. When the IDT is $945^{\circ} \mathrm{C}$, the radial force and torque are about $73 \mathrm{kN}$ and $8 \mathrm{kN} \bullet \mathrm{m}$, respectively. When the IDT is $855^{\circ} \mathrm{C}$, the radial force and torque are about $106 \mathrm{kN}$ and $11.5 \mathrm{kN} \cdot \mathrm{m}$, respectively. The steady radial force at the IDT of $855^{\circ} \mathrm{C}$ increased by $45 \%$ compared with that at $945{ }^{\circ} \mathrm{C}$, and the torque also increased by $44 \%$. This rapid increase in radial force and torque is due to the relatively high resistance to flow of TC4 alloy at relatively low temperature during the rolling process. When the IDT is $885{ }^{\circ} \mathrm{C}$, the non-circularity of the part keep a low level along the axial direction, and the radial force shows a smooth transition during CWR process. The difference is that under the IDT conditions of $945^{\circ} \mathrm{C}$ and $915^{\circ} \mathrm{C}$, the radial force is not uniform in the rolling cycle, and a typical elliptical peak appears at the beginning of rolling, and the elliptical phenomenon occurs in both workpieces.

\subsection{Internal quality analysis}

In the process of plastic forming, the alternating tension-compression stress may lead to the generation of cracks, and the tensile stress along the axis direction may lead to the propagation of micro cracks, with cavities eventually arising as a result. The internal defects will reduce the strength of the formed parts. The distribution of the stress in the stretching zone is given according to Fig. 15. During the CWR process, the tensile-compression stress alternating region is formed in the symmetric center of the cross-section. The stress state in this area changes four times per revolution of the workpiece. The more the number of alternating cycles in the center of the workpiece, the greater the trend of internal defects will occur. The stress in the CWR process increases with the decrease of IDT, which means that the stress state of material is more serious in the rolling process at relatively low temperature. When the IDT is high, the CWR process will make the grain boundary of the material easy to form micro holes [30].

Figure 18 is the internal quality of samples at different IDTs. The microstructure at the central position is shown in Fig. $18 \mathrm{~b}$ to e. Compared with the specified standard GB/T5168-2008, it is difficult to find any internal cave in the centre of the four parts processed at different IDTs under low and high magnifications. This is mainly because the die gap reduces the interaction time between the dies and the workpiece, reduces the number of alternating cycles of tension-compression stress, and prevents the occurrence of central defects. 

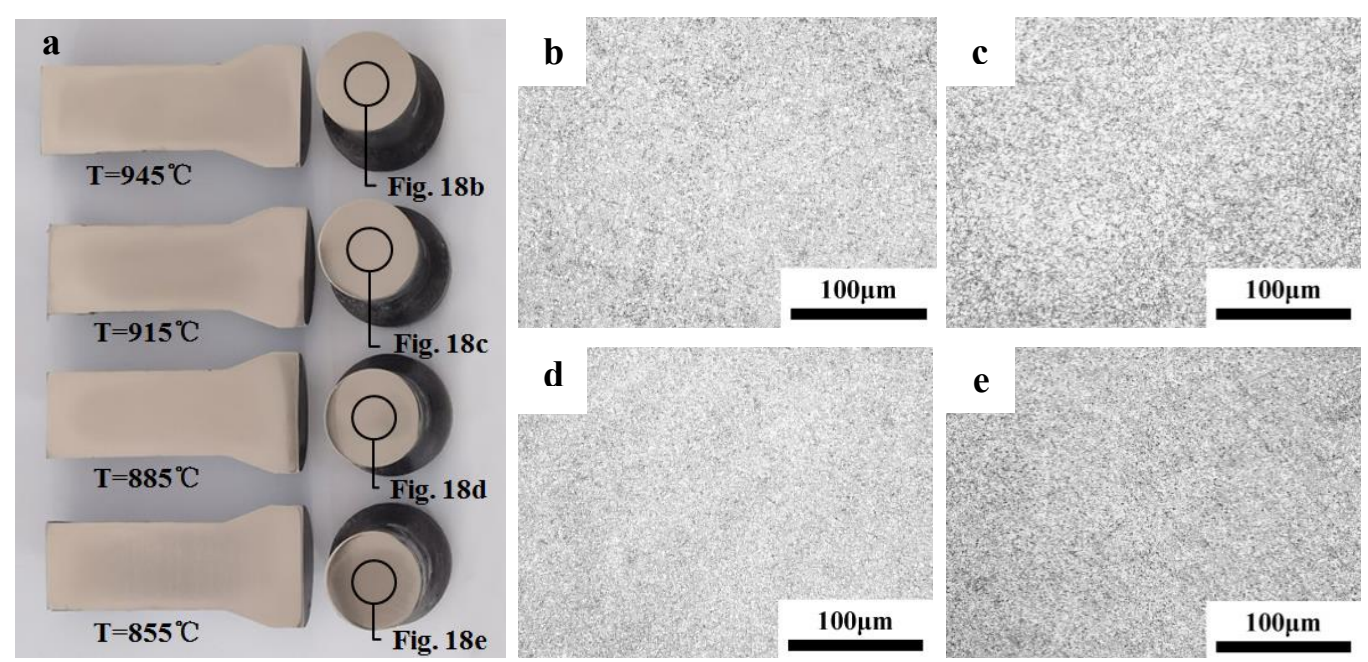

Fig. 18 Internal quality of parts at different IDTs: a sectional display of different parts, $\mathbf{b}$

\subsection{Mechanical properties and microstructure}

The mechanical properties of rolled-parts were investigated by the room temperature tensile experiment. Two tensile samples were taken along the axial direction of rolled-parts, their location is shown in Fig. 19, in which samples 1 and 2 are located in the middle and core of finished zone, respectively. The room temperature tensile strengths of the TC4 alloy in its initial state were $933 \mathrm{MPa}$, $856 \mathrm{MPa}$ and $19.6 \%$ for UTS, YS and EI, respectively.

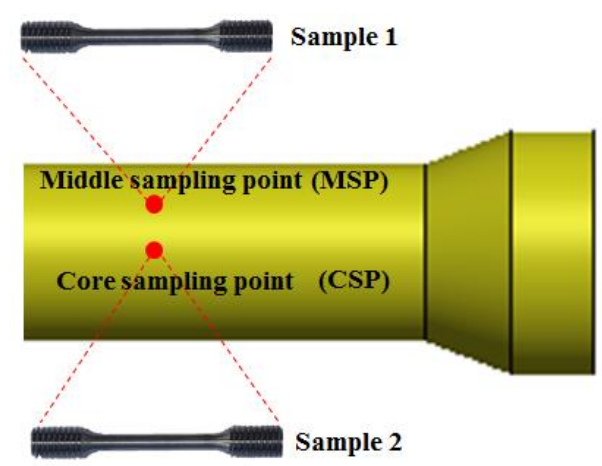

Fig. 19 Mechanical properties and microstructure test sampling position distribution

The room temperature mechanical properties at different IDTs are shown in Fig. 20. The UTS and YS values of rolled workpieces with different IDTs are higher than those of the initial state. It can be seen that the UTS and YS values for both core and middle samples show a tendency to increase and then decrease with increasing IDT, with the maximum value occurring at $885^{\circ} \mathrm{C}$. The maximum UTS and YS values are $987 \mathrm{MPa}$ and $924 \mathrm{MPa}$, respectively, which are 5.7\% and $7.9 \%$ higher than those in the initial state. It has the smallest EI of $16.8 \%$, which is $14.2 \%$ lower than the initial state. 

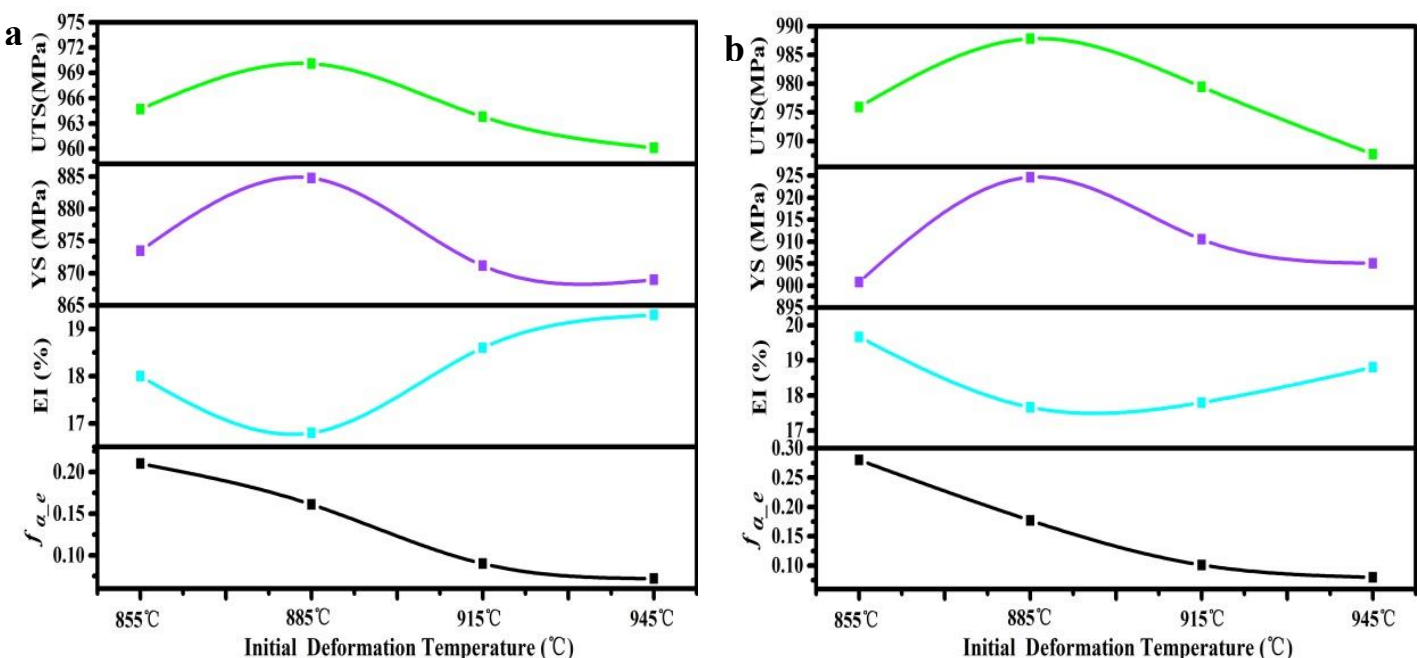

Fig. 20 Comparison of the mechanical properties at different IDTs of a CSP $\mathbf{b}$ MSP

At the same IDT, the UTS and YS in the middle are higher than those in the core, this may be due to the different degrees of deformation of the microstructure along the radial direction from the surface to the center of the part. Because the effective stress and strain gradually decrease from the contact surface along the radial direction to the core position (Fig. 15 and Fig. 16), the deformation of the microstructure according to Fig. $22 \mathrm{a}-\mathrm{h}$ is also decreasing. The thickness of lamellar $\alpha$ phase at the middle is smaller than that at the core. The $\alpha$ phase of the microstructure in the middle and core was refined, which improves the UTS and YS properties of the parts with different IDTs.

From the volume fraction of the equiaxed $\alpha$ phase $\left(f_{\alpha_{-}}\right)$in Fig. $20 \mathrm{a}$ and $\mathrm{b}$, the $f_{\alpha_{-} \text {e }}$ decreases with the increase of IDT. Because the volume fraction of the transition from primary $\alpha$ phase to $\beta$ phase increases with the increase of temperature [28]. The $f_{\alpha \_}$at the CSP corresponding to the different IDTs are lower than that at the MSP. According to Fig. 21a and b, the plastic temperature rise level at the two points is nearly close. The MSP is close to the mold, and the temperature drop is faster than the CSP. The deformation of the MSP during rolling was larger than that of the CSP, and the lamellar $\alpha$ phase undergoes equiaxed transformation, which promotes the increase of the $f_{\alpha \_ \text {e. }}$
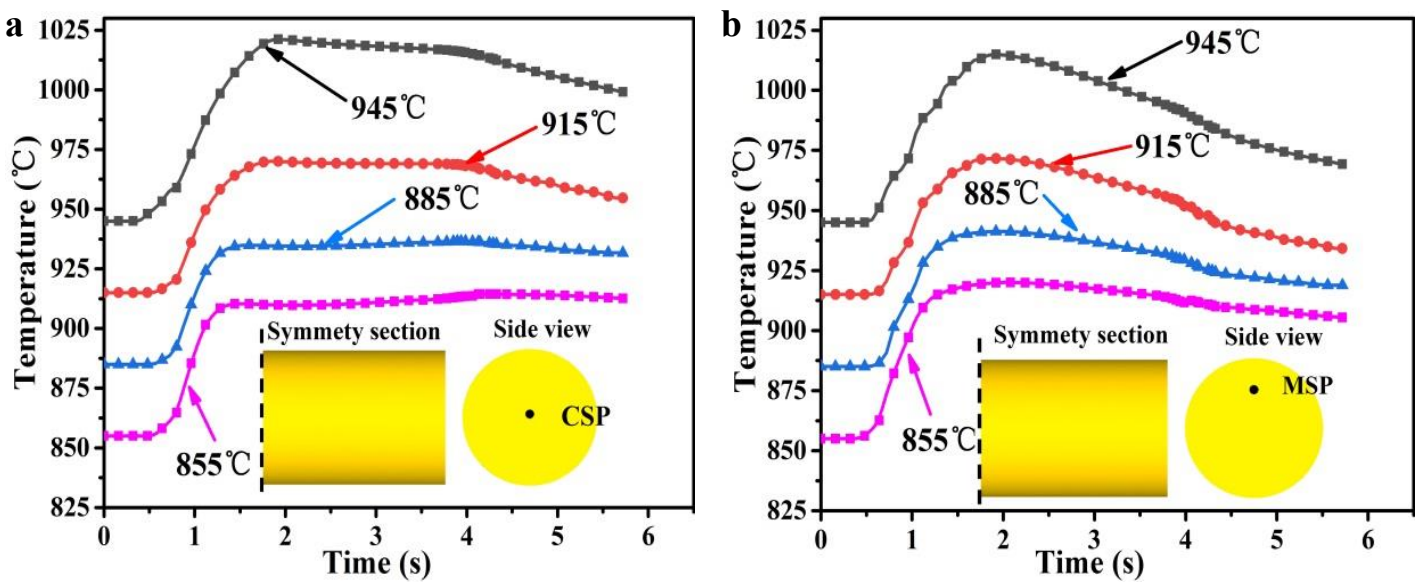

Fig. 21 Temperature distribution of CWR forming TC4 alloy in symmetry sections: a CSP, b MSP

It can be seen from Fig. 22a-b and Fig. 20, when the IDT is reduced to $855^{\circ} \mathrm{C}$, the $f_{\alpha_{-}}$e value in the microstructure is the largest. With the increase of the $f_{\alpha_{-} \mathrm{e}}$, the stability of the residual $\beta$ matrix is also higher [31], which reduces the driving force for the nucleation and growth of the secondary $\alpha$ 
phase, and further increases the EI value of the material and decreases the UTS and YS values. There are many lamellar secondary $\alpha$ phases with small length-width ratio in the microstructure of Fig. 22c and $d$. The lower length-width ratio of the secondary $\alpha$ phase means that the smaller the clusters with the same orientation arranged between the secondary $\alpha$ phase and $\beta$ phase, the more the corresponding clusters. As a result, the crack is more likely to encounter obstacles in the process of propagation, resulting in increased tensile strength of the material [26]. The secondary $\alpha$ phase cluster distribution in the microstructure is mostly parallel to each other. The same $\alpha$ cluster has the same habit plane. At the beginning of sliding, the coarse slip band can be formed through the parallel $\alpha$ cluster without hindrance. Dislocation plugs are easily generated at the grain boundary of $\alpha$, resulting in uneven deformation in small regions. This promotes the formation and development of voids, and leads to premature fracture and poor plasticity. With the increase of IDT, a large number of primary $\alpha$ phase and lamellar secondary $\alpha$ phase transformed into $\beta$ phase. The number of grain boundaries decrease, which reduce the strength of the material. Compared with the microstructure with IDT of $885{ }^{\circ} \mathrm{C}$, many lamellar secondary $\alpha$ phase with large interlayer spacing appear in the microstructure of Fig. $22 \mathrm{e}$ to h, and the thickness of lamellar secondary $\alpha$ phase increases and the distribution is chaotic. This makes the UTS and YS of the material decreased, and the EI value increased slightly.
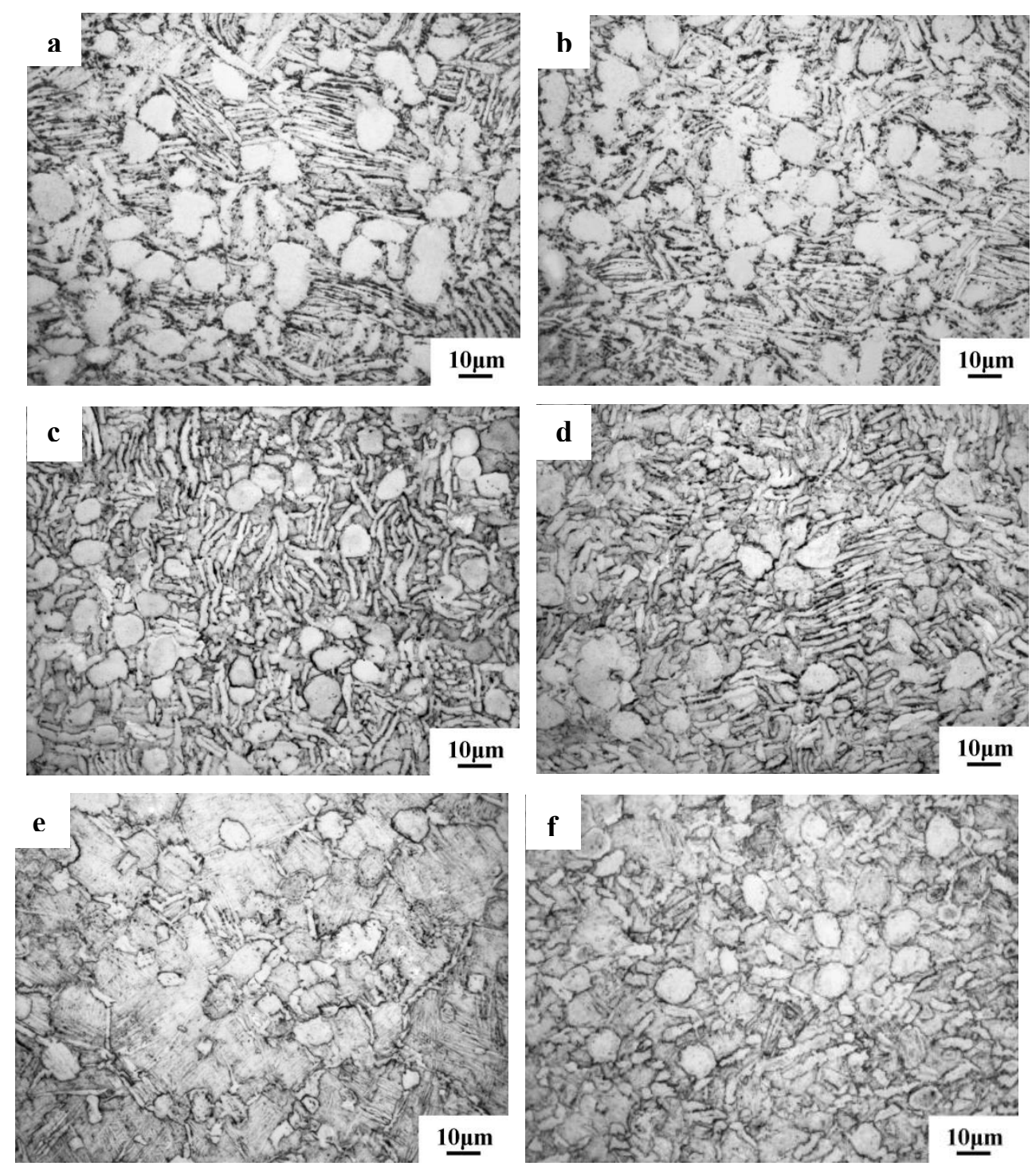

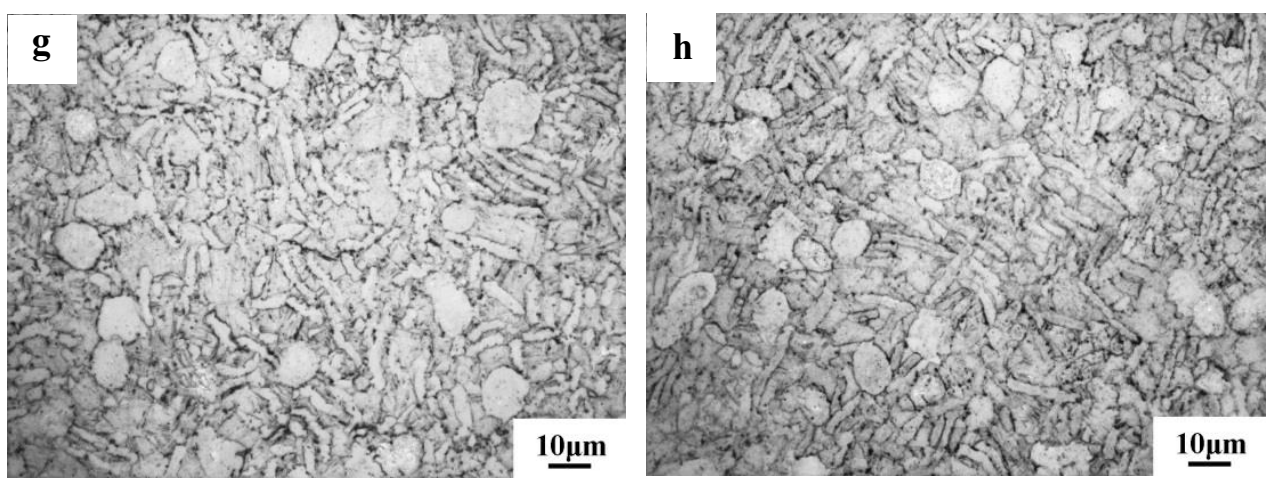

Fig. 22 The microstructure of CSP and MSP of parts at different IDTs: $\mathbf{a} \mathrm{T}=855^{\circ} \mathrm{C}, \mathrm{CSP}$; $\mathbf{b}$ $\mathrm{T}=855^{\circ} \mathrm{C}, \mathrm{MSP} ; \mathbf{c ~ T}=885^{\circ} \mathrm{C}, \mathrm{CSP} ; \mathbf{d ~ T}=885^{\circ} \mathrm{C}, \mathrm{MSP} ;(\mathrm{e}) \mathrm{T}=915^{\circ} \mathrm{C}, \mathrm{CSP} ; \mathbf{f} \mathrm{T}=915^{\circ} \mathrm{C}, \mathrm{MSP} ; \mathbf{g}$ $\mathrm{T}=945^{\circ} \mathrm{C}, \mathrm{CSP} ; \mathbf{h} \mathrm{T}=945^{\circ} \mathrm{C}, \mathrm{MSP}$

\section{Conclusions}

1. The surface steps of the parts are mainly caused by the elliptical deformation in the rolling process. With the increase of IDT, the elliptical deformation is serious, so there are obvious steps on the surface of the rolled parts after rolling at high temperatures. After several IDT experiments, the results showed that surface quality of the rolled workpiece is the best at $885^{\circ} \mathrm{C}$.

2. Compared with the CWR process at different IDTs, the lower the IDT is, the greater the radial force and torque are required. When the IDT is $945^{\circ} \mathrm{C}$, the radial force and torque are about $73 \mathrm{kN}$ and $8 \mathrm{kN} \cdot \mathrm{m}$, respectively. When the IDT is $855^{\circ} \mathrm{C}$, the radial force and torque are about $106 \mathrm{kN}$ and $11.5 \mathrm{kN} \cdot \mathrm{m}$, respectively, which are 1.4 times higher than those at $945^{\circ} \mathrm{C}$.

3. The die gap reduces the interaction time between the die and the workpiece and the number of alternating cycles of tensile-compression stress in the rolled workpiece, resulting in no internal defects in the TC4 alloy rolled workpiece in the high IDT range of 855-945 ${ }^{\circ} \mathrm{C}$.

4. The mechanical properties of UTS, YS and EI of TC4 alloy were jointly affected by primary $\alpha$ phase content and microstructure morphology. The microstructure of the parts was refined after rolling, and the mechanical properties were improved compared with the initial state. At the IDT of $885^{\circ} \mathrm{C}$, the UTS, YS and EI were $987 \mathrm{MPa}, 924 \mathrm{MPa}$ and $16.8 \%$, respectively. It shows that the parts with high tensile strength and elongation can be obtained by hot CWR process, which can meet the requirements of the mechanical properties of the lower arm preform.

\section{Acknowledgements}

This work is supported by the National Key R\&D Program of China (Grant No. 2018YFB1307900), and the National Natural Science Foundation of China (Grant No. 51875036)

Authors' contributions Peiai Li: conceptualization, investigation, methodology, data curation, writing-original draft, reviewing and editing.

Baoyu Wang: supervision, conceptualization, methodology, funding acquisition, reviewing and editing.

Pengni Feng: supervision, methodology, reviewing and editing.

Jinxia Shen: supervision, methodology, reviewing and editing.

Jiapeng Wang: supervision, methodology, reviewing and editing. 
Data availability The datasets generated and/or analysed during the current study are available from the corresponding author on reasonable request.

Conflicts of interest The authors have no conflicts of interest to declare that are relevant to the content of this article.

Ethical approval The article follows the guidelines of the Committee on Publication Ethics (COPE) and involves no studies on human or animal subjects.

Consent to participate Applicable.

\section{Consent to publish Applicable.}

\section{References}

[1] Boyer RR (1996) An overview on the use of titanium in the aerospace industry. Mater Sci Eng A 213(1-2):103-114. https://doi.org/10.1016/0921-5093(96)10233-1

[2] Leyens C, Peters M (2003) Titanium and titanium alloys: fundamentals and applications. Publ House Wiley-VCH 38(6):401.

[3] Poondla N, Srivatsan TS, Patnaik A, Petraroli M (2009) A study of the microstructure and hardness of two titanium alloys: commercially pure and Ti-6Al-4V. J Alloy Compd 486(1-2):162-167. https://doi.org/10.1016/j.jallcom.2009.06.172

[4] Arrazola PJ, Garay A, Lriarte LM, Armendia M, Marya S, Maître FL (2009) Machinability of titanium alloys (Ti6Al4V and Ti555.3). J Mater Process Tech 209(5):2223-2230. https://doi.org/10.1016/j.jmatprotec.2008.06.020

[5] Guo P, Zhao YQ, Zeng WD, Hong Q (2013) The effect of microstructure on the mechanical properties of TC4-DT titanium alloys. Mater Sci Eng A 563(2):106-111. https://doi.org/10.1016/j.msea.2012.11.033

[6] Li JL, Wang BY, Fang S, Chen P (2020) A new process chain combining cross-wedge rolling and isothermal forging for the forming of titanium alloy turbine blades. Int J Adv Manuf Tech 108(5-6):1827-1838.

[7] Hu ZH, Zhang KS, Wang BY, Shu XD, Yang CP (2004) Forming technology and simulation of cross wedge rolling parts. Metall Ind Press, Beijing (in Chinese)

[8] Ji HC, Liu JP, Wang BY, Zheng ZH, Huang JH, Hu ZH (2015) Cross-wedge rolling of a 4Cr9Si2 hollow valve: explorative experiment and finite element simulation. Int J Adv Manuf Tech 77(1-4):15-26. https://doi.org/10.1007/s00170-014-6363-9

[9] Ji HC, Liu JP, Wang BY, Zhang ZR, Zhang T, Hu ZH (2015) Numerical analysis and experiment on cross wedge rolling and forging for engine valves. J Mater Process Tech 221:233-242. https://doi.org/10.1016/j.jmatprotec.2015.02.007

[10] Li Q, Lovell MR, Slaughter W, Tagavi K (2002) Investigation of the morphology of internal defects in cross wedge rolling. J Mater Process Tech 125-126(3):248-257. https://doi.org/10.1016/S0924-0136(02)00303-5

[11] Jia Z, Zhou J, Ji JJ, Lei ZZ, Xiang D, Sun XT (2013) Influence analysis of area reduction for necking in twice-stage cross wedge rolling. Int J Adv Manuf Tech. 66(9-12):1407-1413. https://doi.org/10.1007/s00170-012-4418-3 
[12] Pater Z (1999) Numerical simulation of the cross wedge rolling process including upsetting. J Mater Process Tech 92-93(0):468-473. https://doi.org/10.1016/S0924-0136(99)00231-9

[13] Pater Z (2000) Theoretical and experimental analysis of cross wedge rolling process. Int J Mach Tool Manu 40(1):49-63. https://doi.org/10.1016/S0890-6955(99)00047-4

[14] Pater Z (2006) Finite element analysis of cross wedge rolling. J Mater Process Tech 173(2):201-208. https://doi.org/10.1016/j.jmatprotec.2005.11.027

[15] Maraghechi H, Rajabipour F, Pantano CG, Burgos WD (2018) Micro-mechanism of central damage formation during cross wedge rolling. J Mater Process Technol 252:322-332. https://doi.org/10.1016/j.jmatprotec.2017.09.041

[16] Lee HW, Lee GA, Yoon DJ, Choi S, Na KH, Hwang MY (2008) Optimization of design parameters using a response surface method in a cold cross-wedge rolling. J Mater Process Tech 201(1-3):112-117. https://doi.org/10.1016/j.jmatprotec.2007.11.287

[17] Li JG, Liu JP, Hu ZH (2008) Study on influencing factors of torsional deflection in cross wedge rolling. Forg Stamping Technology 33(4):67-71. (in Chinese)

[18] Shu XD, Nie GZ, Li LP (2007) Study on Influence of die void on rolling force during cross wedge rolling. Chin Metall 17(7):38-40. (in Chinese)

[19] Pater Z, Bulzak T, Tomczak J (2016) Cross-wedge rolling of driving shaft from titanium alloy Ti6Al4V. Key Eng Mater 687:125-132. https://doi.org/10.4028/www.scientific.net/KEM.687.125

[20] Çakırcalı M, Kılıçaslan C, Güden M, Kıranlı E, Shchukin VY, Petronko VV (2013) Cross wedge rolling of a Ti6A14V (ELI) alloy: the experimental studies and the finite element simulation of the deformation and failure. Int $\mathrm{J}$ Adv Manuf Tech 65(9-12):1273-1287. https://doi.org/10.1007/s00170-012-4256-3

[21] Huang X, Wang BY, Mu YH, Shen JX, Li JL, Zhou J (2019) Investigation on the effect of mandrels on hollow shafts in cross-wedge rolling. Int J Adv Manuf Tech 102(1-4):443-455. https://doi.org/10.1007/s00170-018-3093-4

[22] Ji HC, Dong JW, Xin L, Huang XM, Liu JP (2018) Numerical and experimental study on the thermodynamic coupling of Ti-6Al-4V blade preforms by cross wedge rolling. Metals 8(12):1054. https://doi.org/10.3390/met8121054

[23] Li JL, Wang BY, Ji HC, Huang X, Tang XF, Ma WP (2017) Effects of the cross-wedge rolling parameters on the formability of Ti-6Al-4V alloy. Int J Adv Manuf Tech 92(5-8):2217-2229. https://doi.org/10.1007/s00170-017-0263-8

[24] Shi ZF, Guo HZ, Liu R, Wang XC, Yao ZK (2015) Microstructure and mechanical properties of TC21 titanium alloy by near-isothermal forging. Trans Nonferr Met Soc 25(1):72-79. https://doi.org/10.1016/S1003-6326(15)63580-4

[25] Zhang ZX, Qu SJ, Feng AH, Hu X, Shen J (2019) Microstructural mechanisms during multidirectional isothermal forging of as-cast Ti-6Al-4V alloy with an initial lamellar microstructure. J Alloy Compd 773:277-87. https://doi.org/10.1016/j.jallcom.2018.09.220

[26] Zhai DJ, Shui Y, Yuan M, Zhang YY, He YB (2019) Effects of content and morphology of $\alpha$ phase on microstructure and mechanical properties of TC4 alloy. Heat Treat Met 44(10):129-134. (in Chinese)

[27] Wang M, Yang H, Zhang C, Guo LG (2013) Microstructure evolution modeling of titanium alloy large ring in hot ring rolling. Int $\mathrm{J}$ Adv Manuf Tech 66(9-12):1427-1437. https://doi.org/10.1007/s00170-012-4420-9

[28] Li JL, Wang BY, Qin Y, Fang S, Huang X, Chen P (2019) Investigating the effects of process 
parameters on the cross wedge rolling of TC6 alloy based on temperature and strain rate sensitivities. Int $\mathrm{J}$ Adv Manuf Tech https://doi.org/10.1007/s00170-019-03461-3

[29] Peng XN, Guo HZ, Shi ZF (2013) Constitutive equations for high temperature flow stress of TC4-DT alloy incorporating strain, strain rate and temperature. Mater Design 50(17):198-206. https://doi.org/10.1016/j.matdes.2013.03.009

[30] Huang X, Wang BY, Zhou J, Ji HC, Mu YH, Li JL (2017) Comparative study of warm and hot cross-wedge rolling: numerical simulation and experimental trial. Int $\mathrm{J}$ Adv Manuf Tech 92(9-12):3541-3551. https://doi.org/10.1007/s00170-017-0399-6

[31] Ren L, Xiao W, Chang H, Zhao Y, Ma C, Zhou L (2018) Microstructural tailoring and mechanical properties of a multi-alloyed near $\beta$ titanium alloy Ti-5321 with various heat treatment. Mater Sci Eng: A 711:553-561. https://doi.org/10.1016/j.msea.2017.11.029 


\section{Figures}

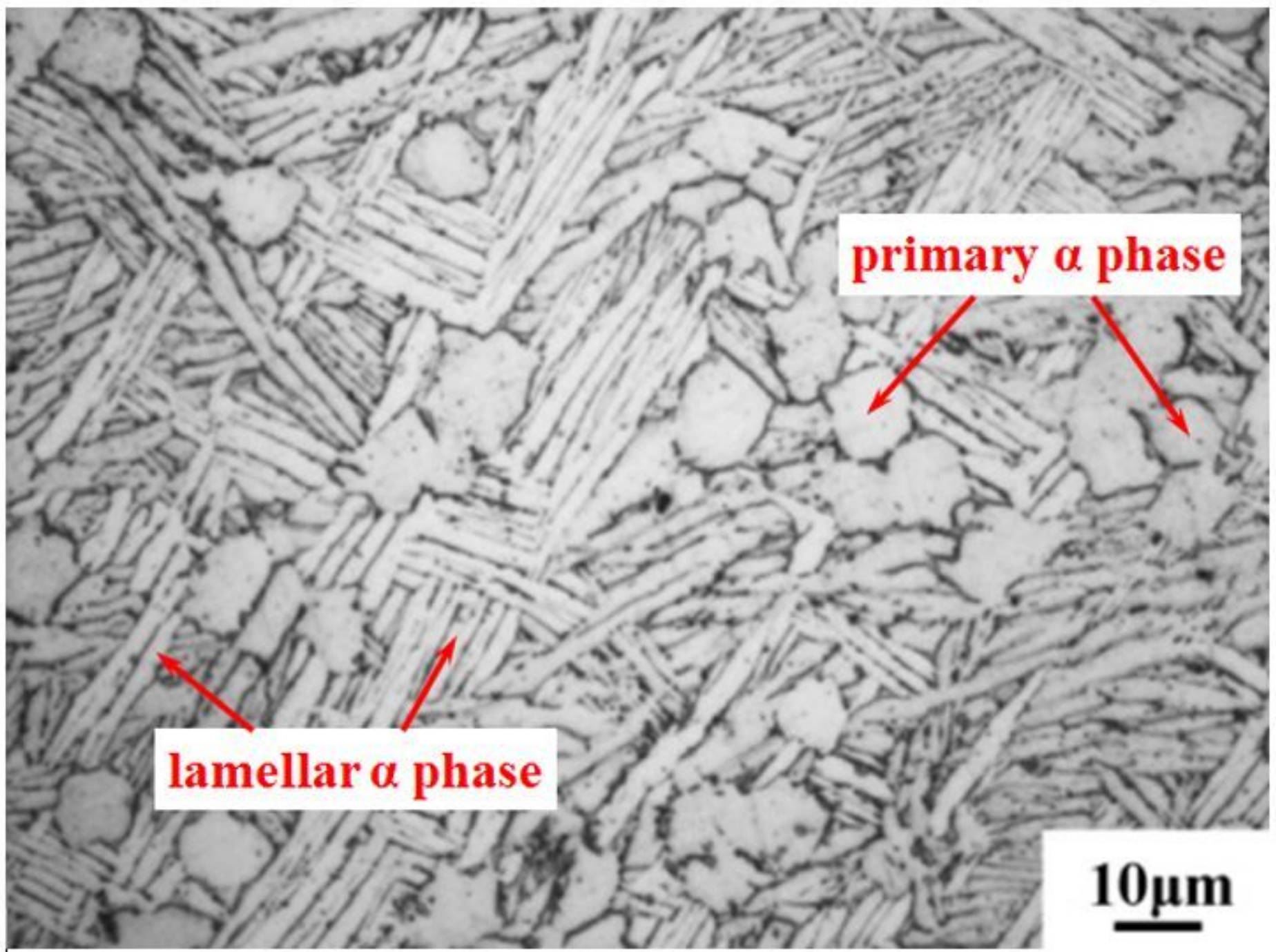

Figure 1

Optical micrograph of received TC4 alloy 

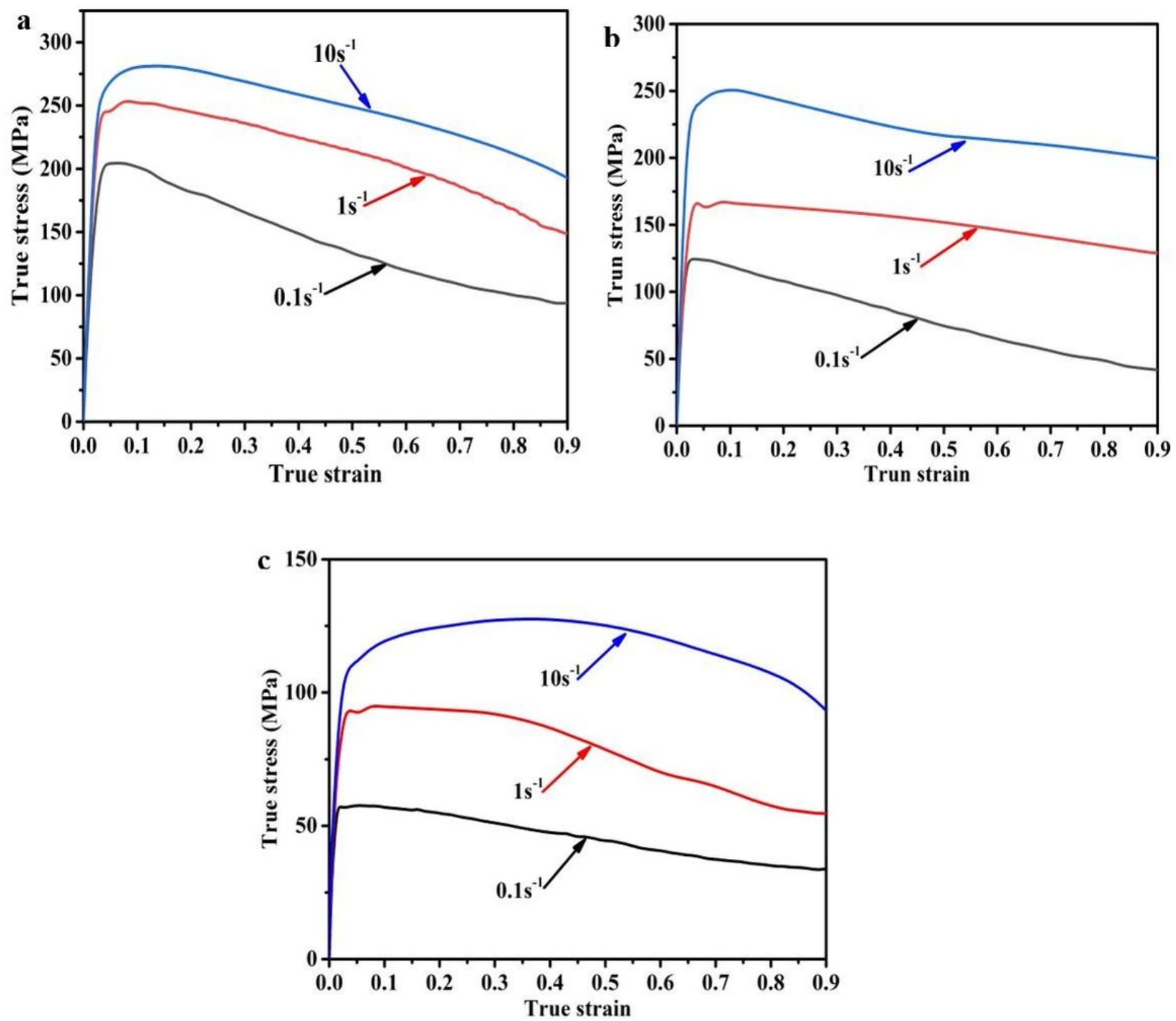

Figure 2

True stress-strain curves of TC4 alloy: a $850{ }^{\circ} \mathrm{C}$, b $900{ }^{\circ} \mathrm{C}, \mathrm{c} 950{ }^{\circ} \mathrm{C}$ 


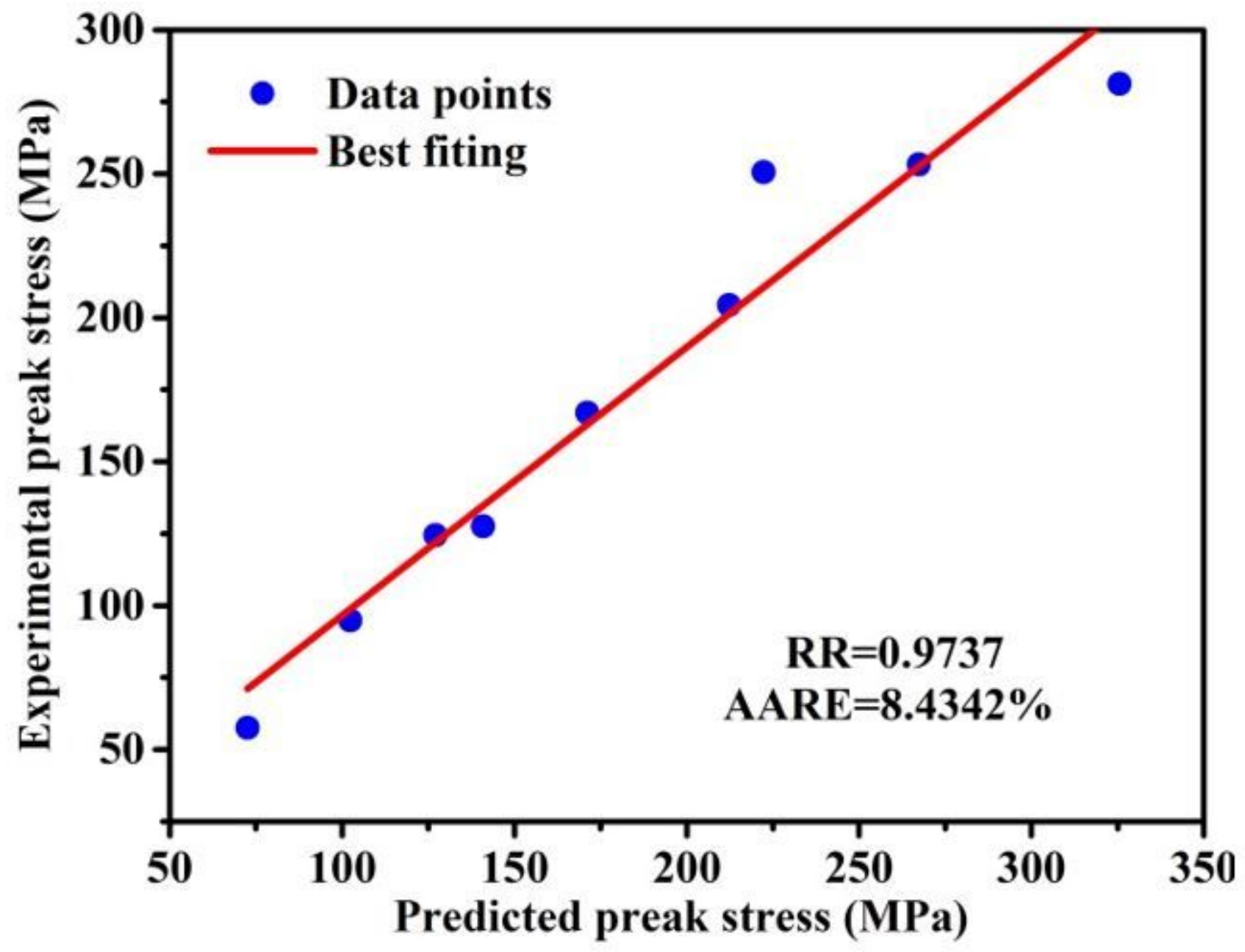

Figure 3

Comparison of predicted peak stress and experimental peak stress 


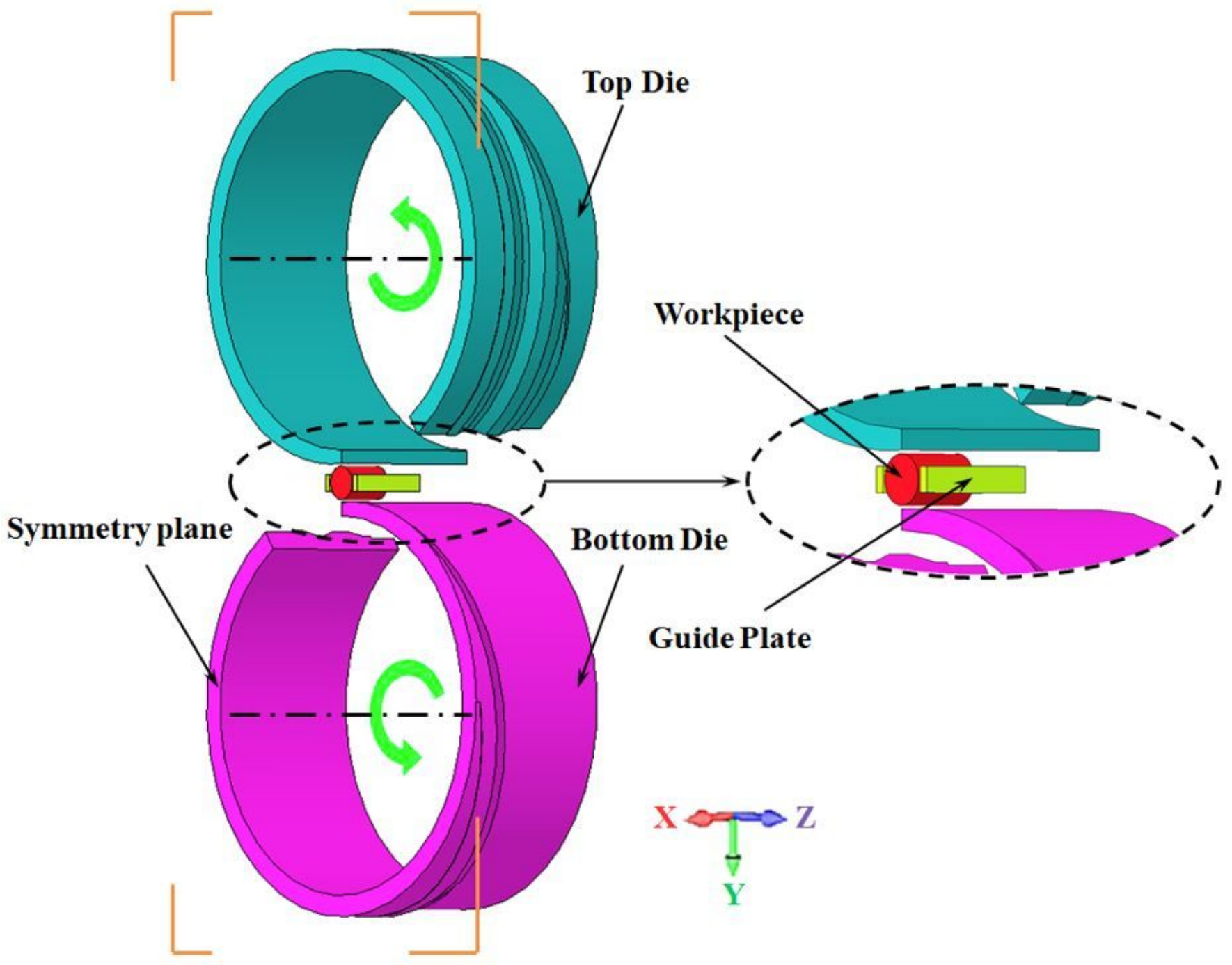

Figure 4

FEM of CWR for TC4 alloy 


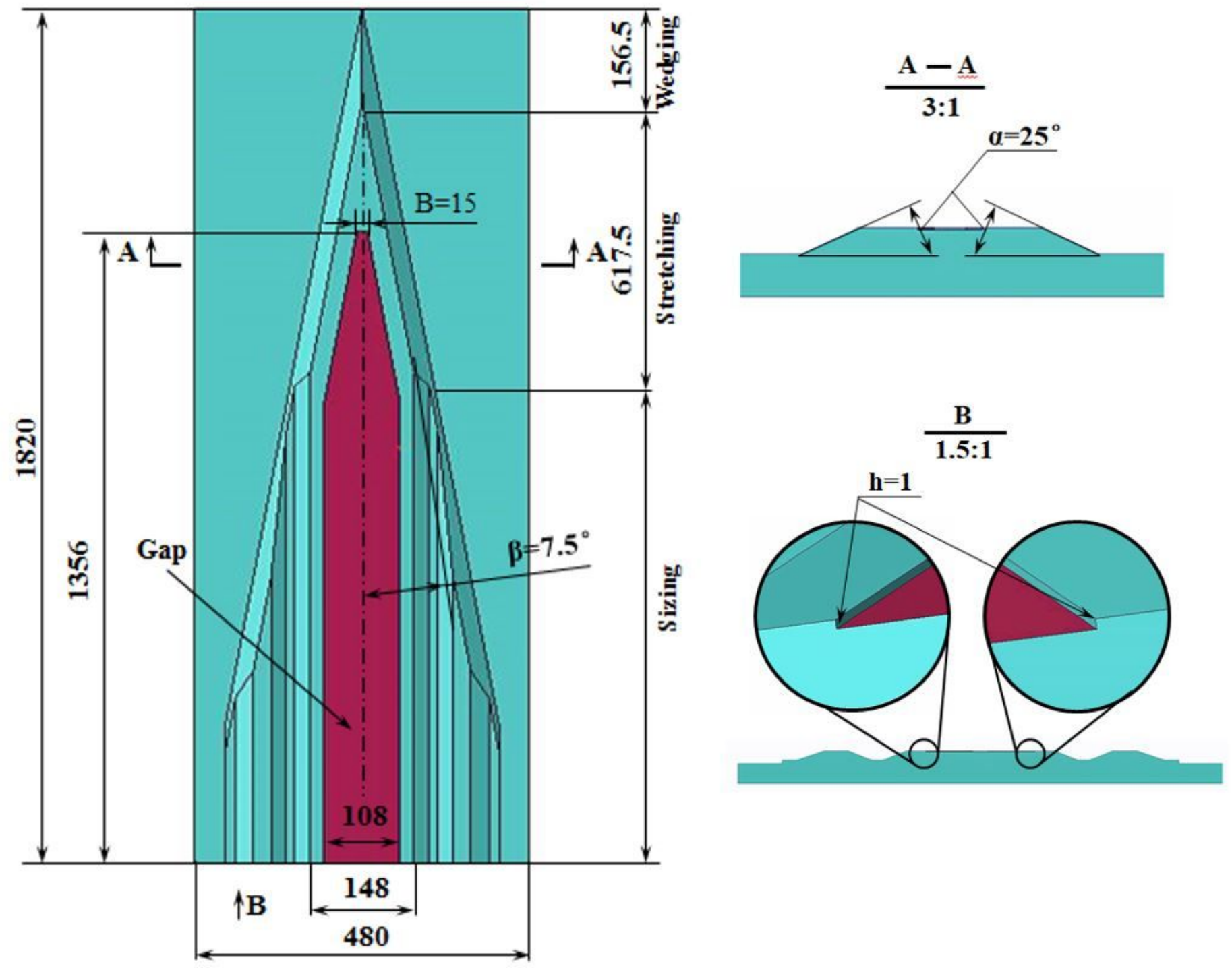

Figure 5

Forming wedge tool parameters for $\mathrm{H} 630$ rolling mill 


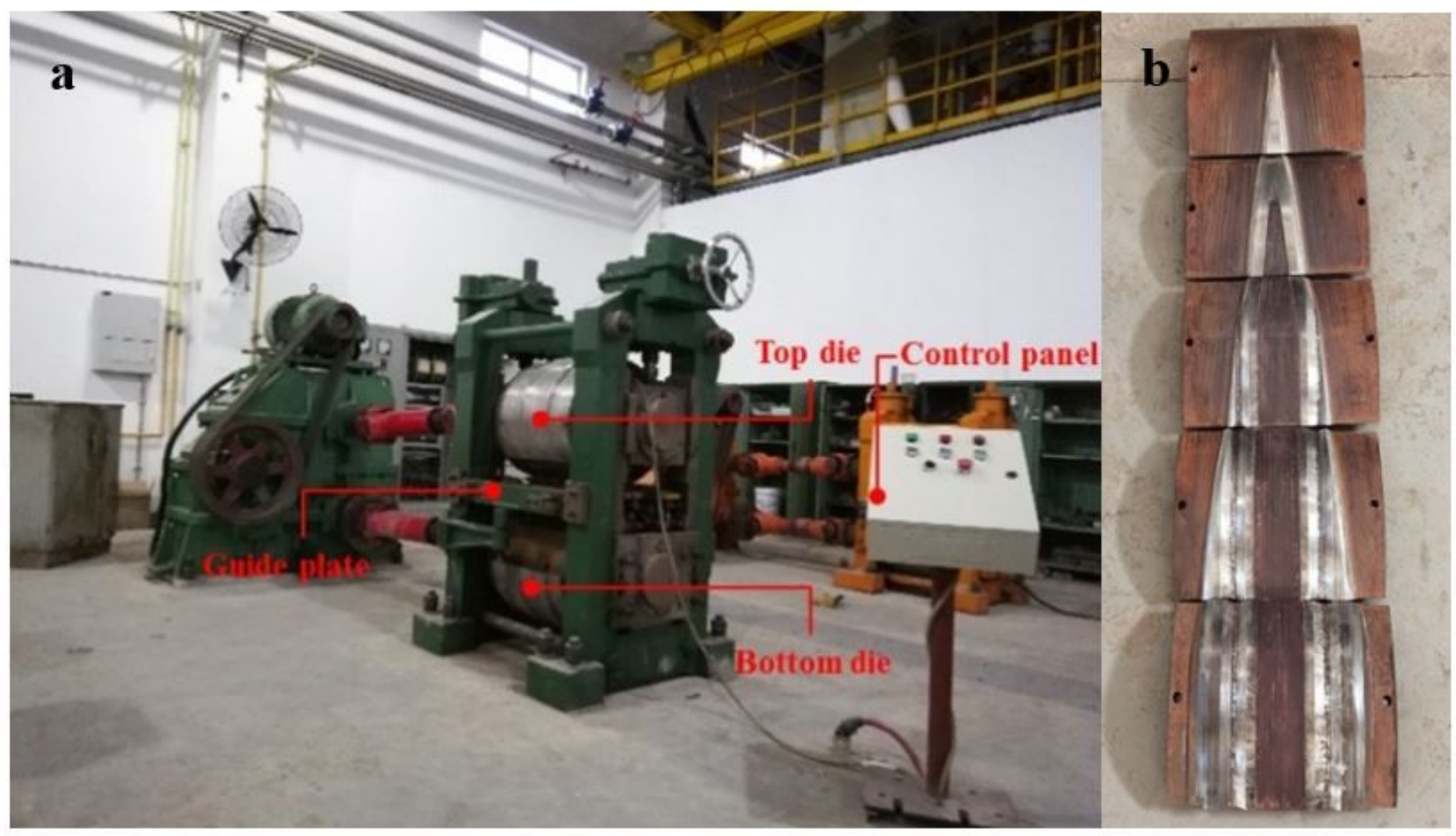

Figure 6

Experimental equipment and manufactured die: a H630 mill, b Forming wedge dies 


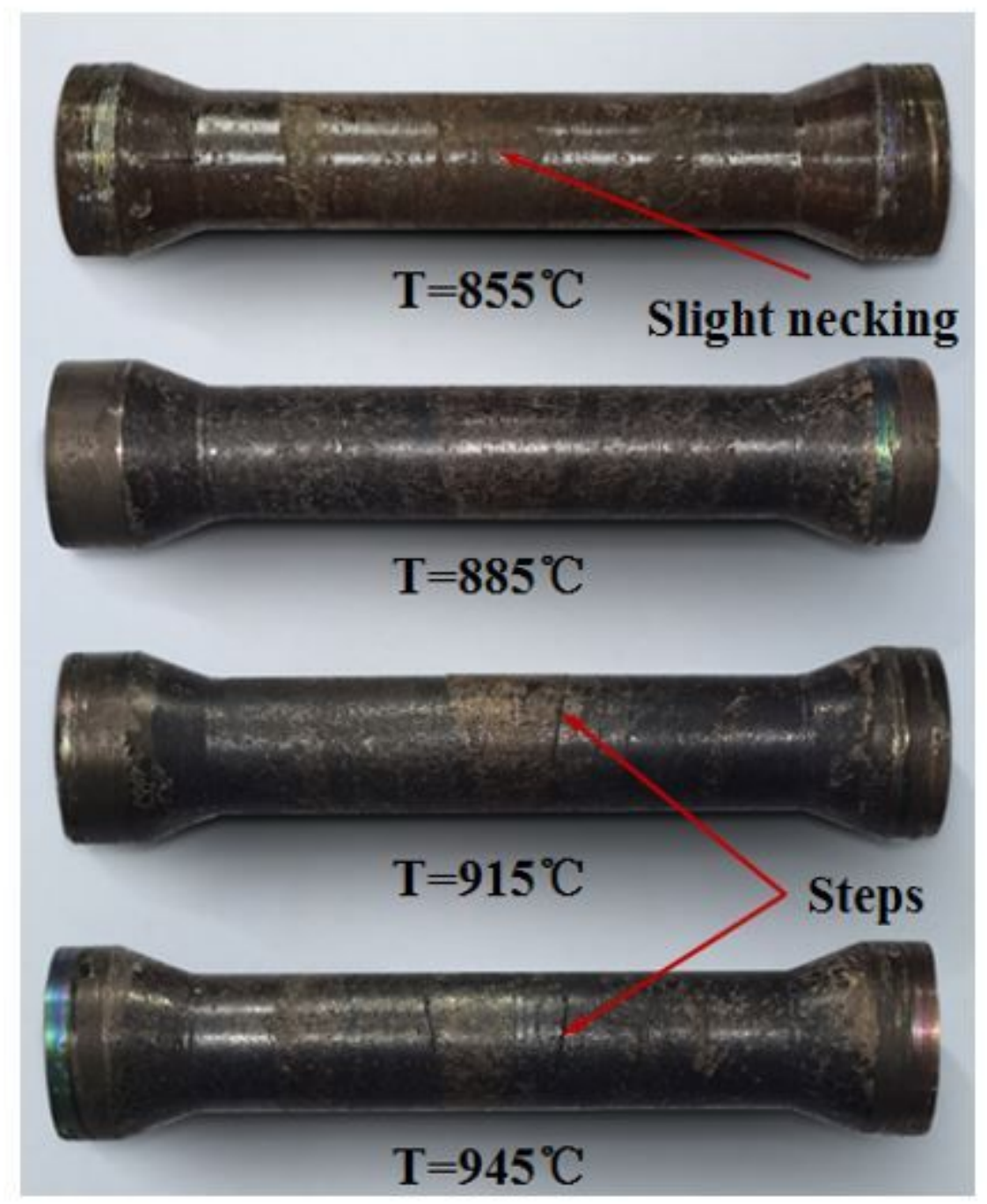

Figure 7

The parts of rolled 


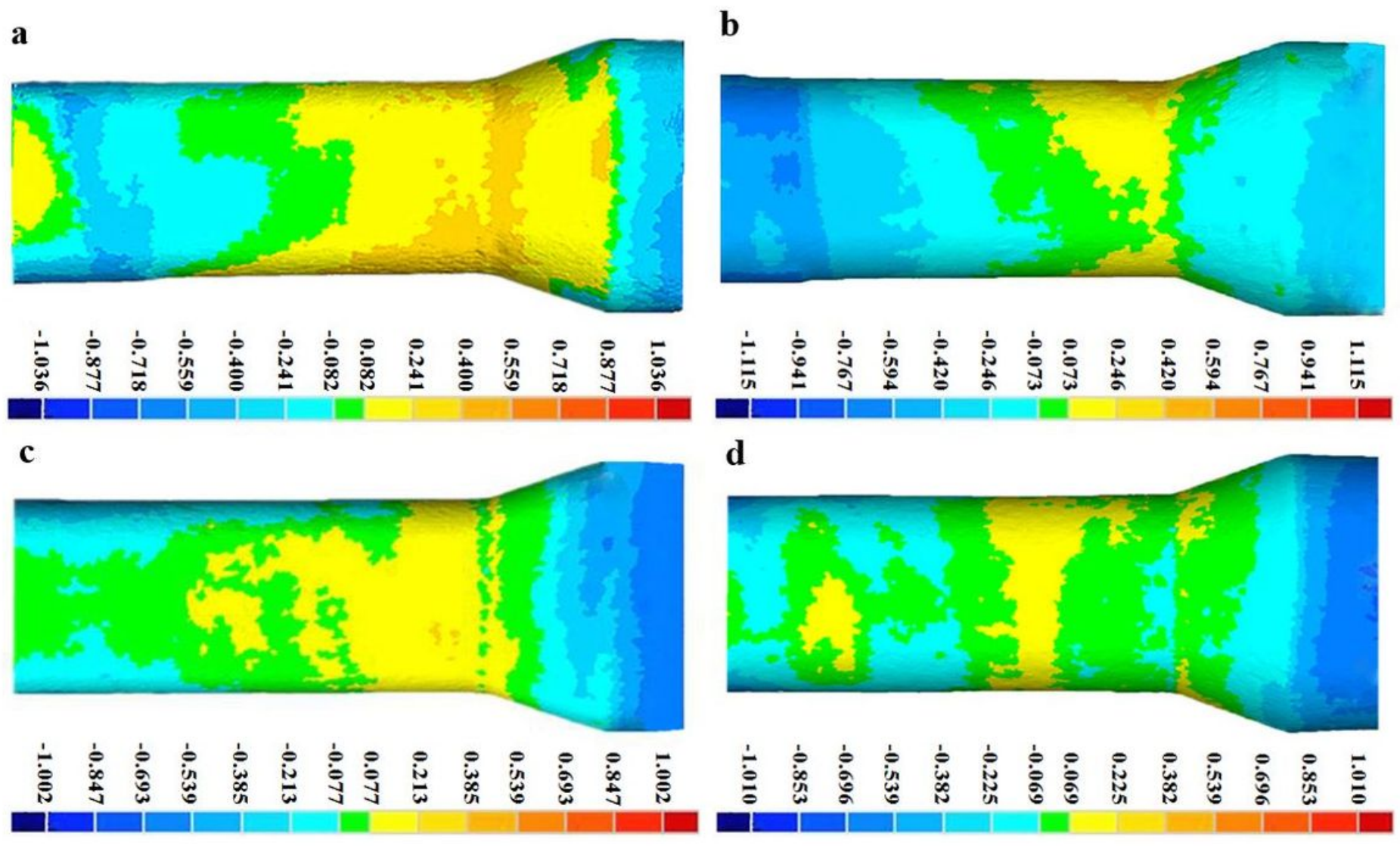

Figure 8

Comparison of TC4 Alloy CWR Parts and simulated results: a IDT at $945^{\circ} \mathrm{C}$, b IDT at $915^{\circ} \mathrm{C}, \mathrm{c} \mathrm{IDT}$ at $885^{\circ} \mathrm{C}$, d IDT at $855^{\circ} \mathrm{C}$ 


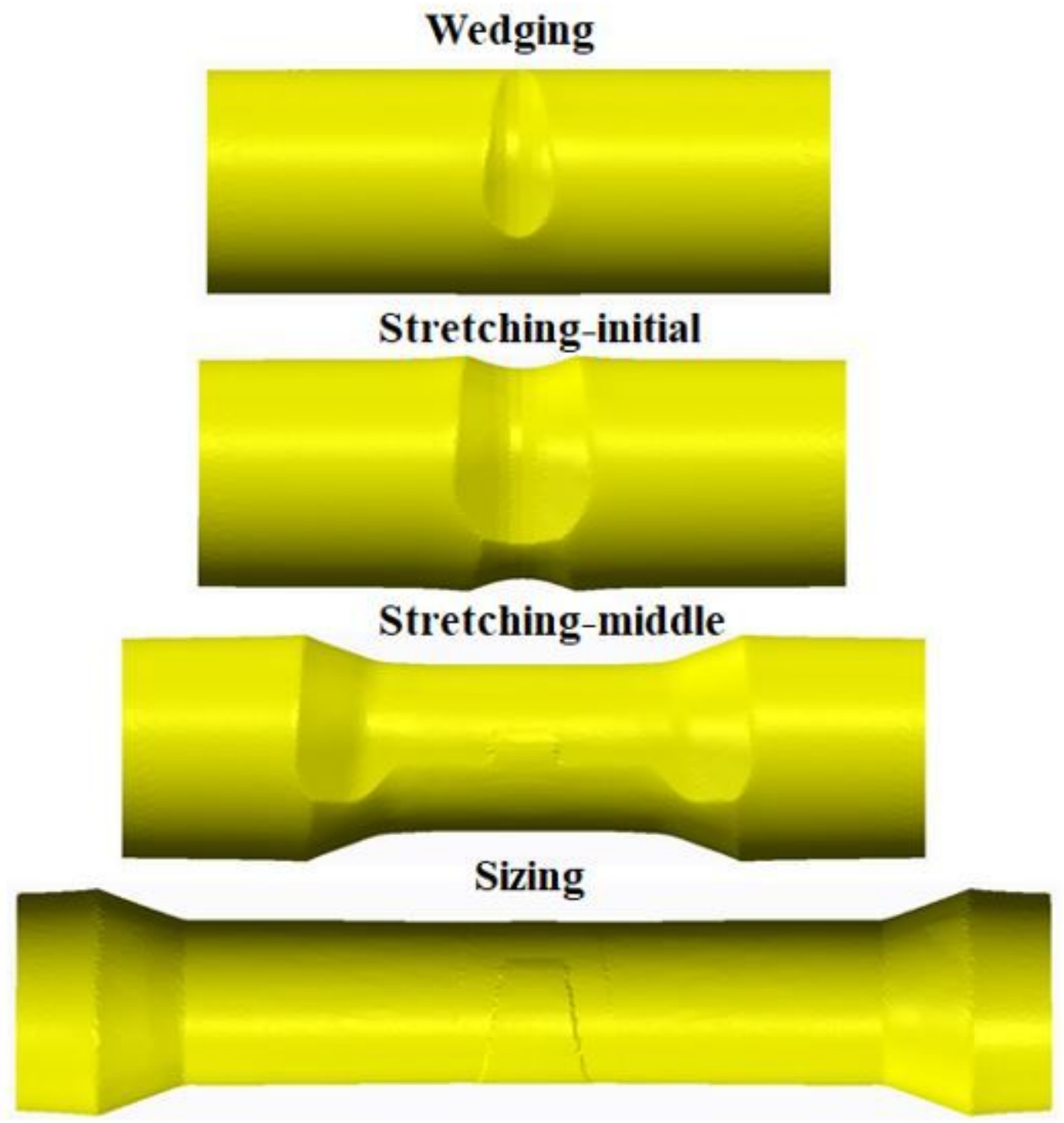

Figure 9

Different stages of CWR and step forming 

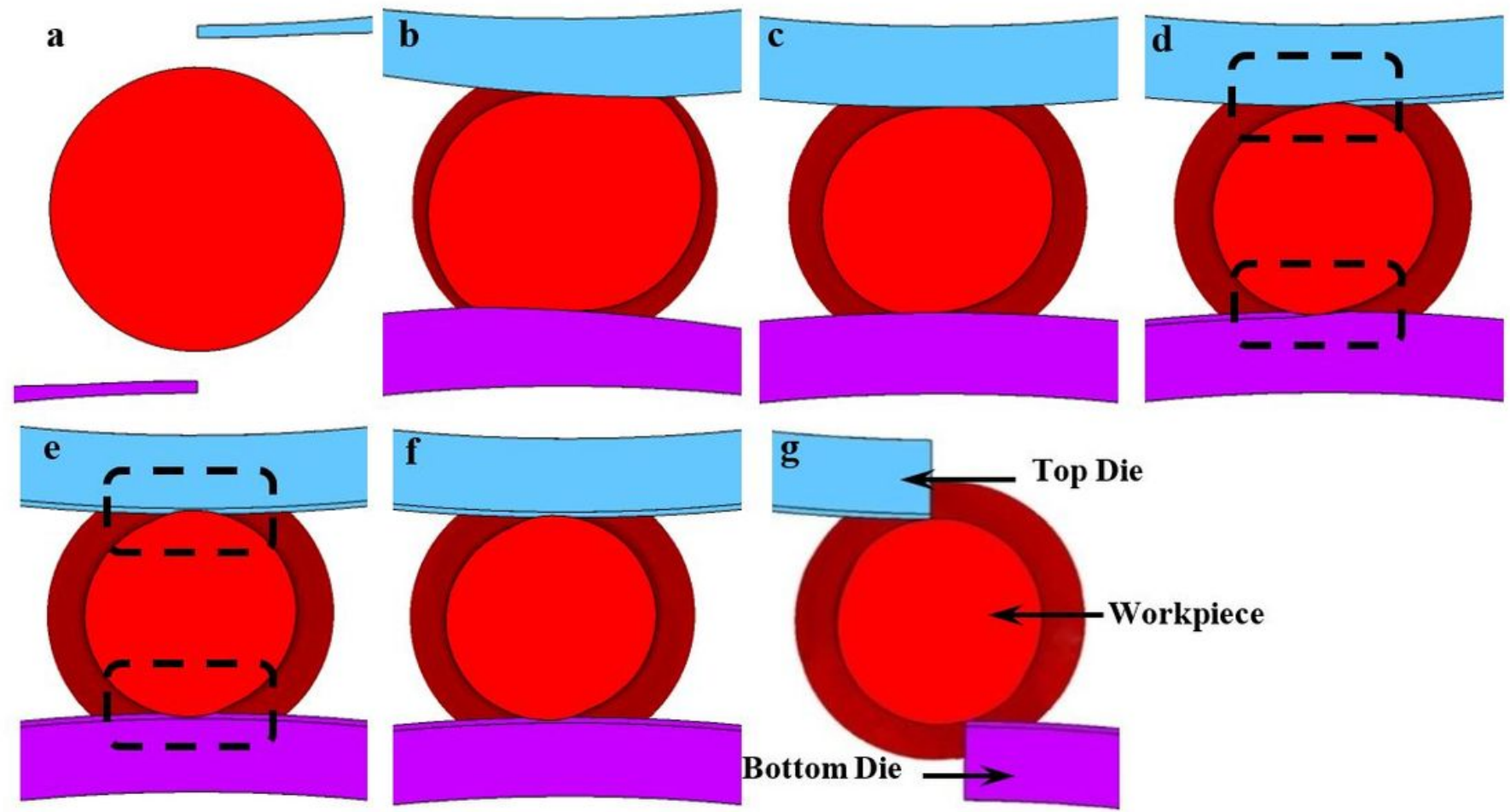

Figure 10

Cross-section profile during forming process at IDT of $945^{\circ} \mathrm{C}$ : a initial status $\mathrm{t}=0 \mathrm{~s}$, $\mathrm{b}$ wedging stage $t=0.8 \mathrm{~s}$, $c$ stretching stage $t=1.52 \mathrm{~s}$, $d$ preparing for the gap stage $t=1.84 \mathrm{~s}$, e gap stage $t=2.4 \mathrm{~s}, \mathrm{f}$ sizing stage $\mathrm{t}=3.2 \mathrm{~s}$, g completion status $\mathrm{t}=5.64 \mathrm{~s}$
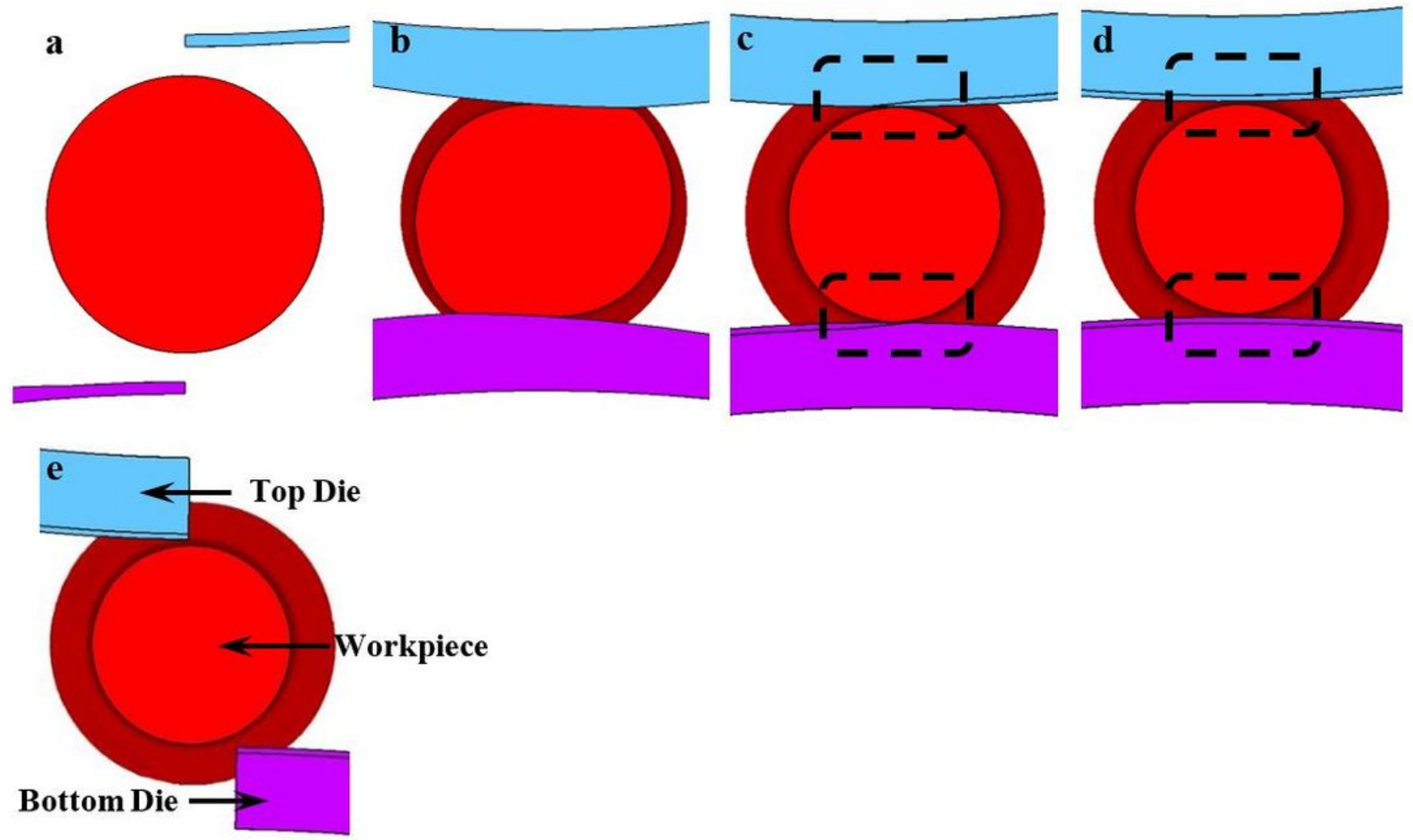


\section{Figure 11}

Cross-section profile during forming process at IDT of $885^{\circ} \mathrm{C}$ : a initial status $\mathrm{t}=0 \mathrm{~s}$, $\mathrm{b}$ wedging stage $t=0.8 \mathrm{~s}$, c preparing for the gap stage $t=1.84 \mathrm{~s}$, $d$ sizing stage $t=3.2 \mathrm{~s}$, e completion status $t=5.64 \mathrm{~s}$

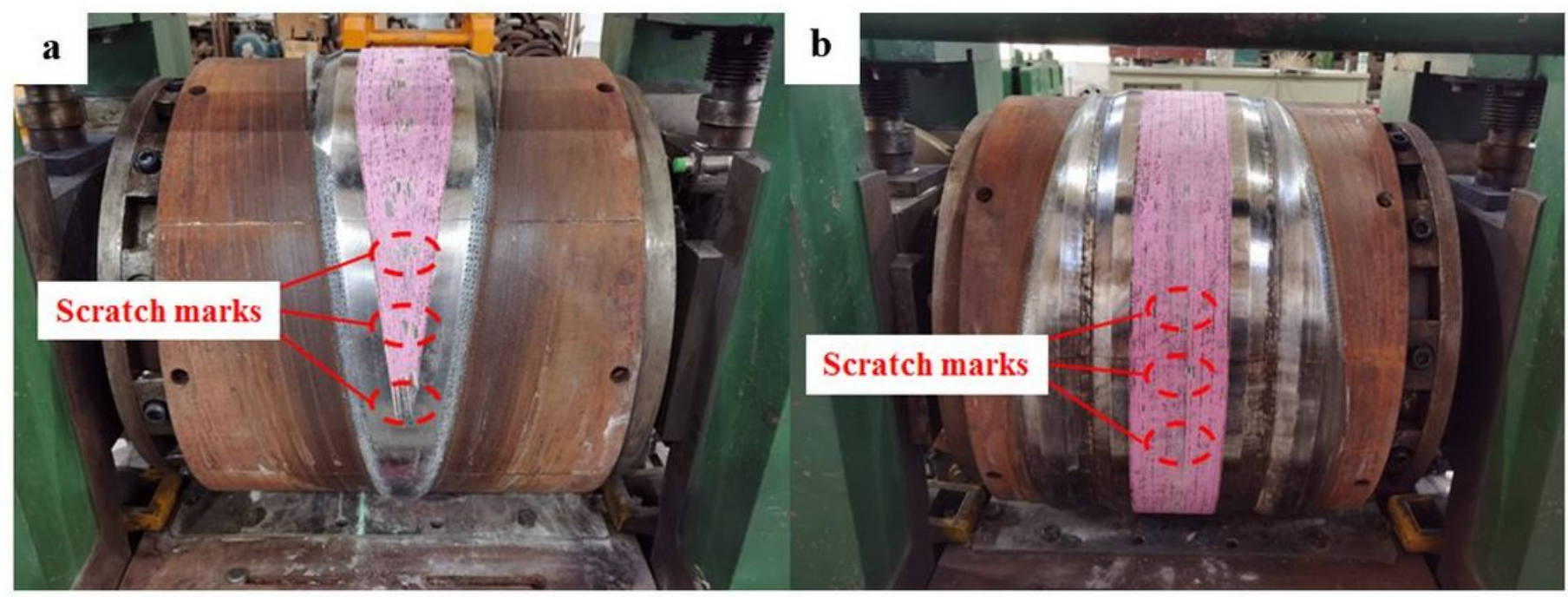

Figure 12

The distribution of scratch marks on the surface of the die gap area: a scratch marks in stretching zone, $b$ scratch marks in sizing zone

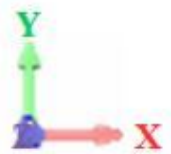

\section{Symmetrical section Termination section}

FEM
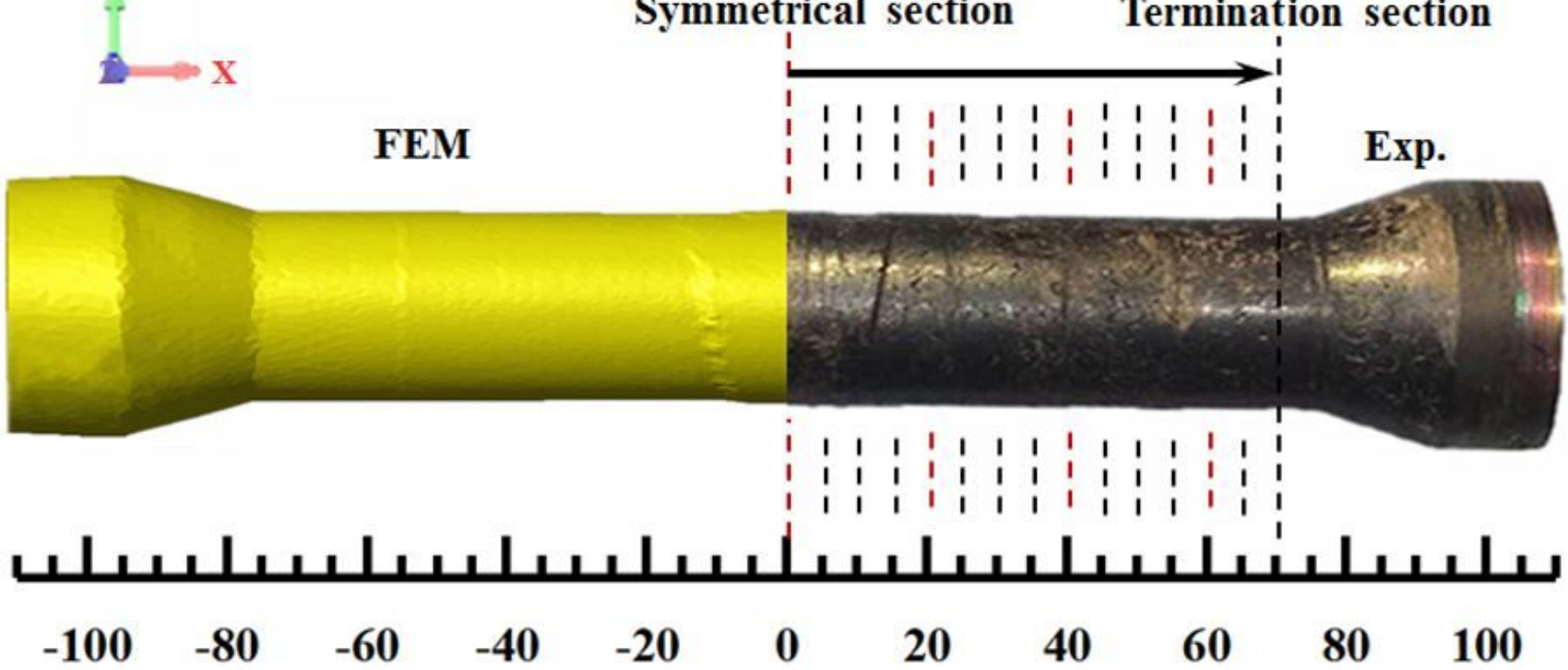

Figure 13

Cross-section distribution position 

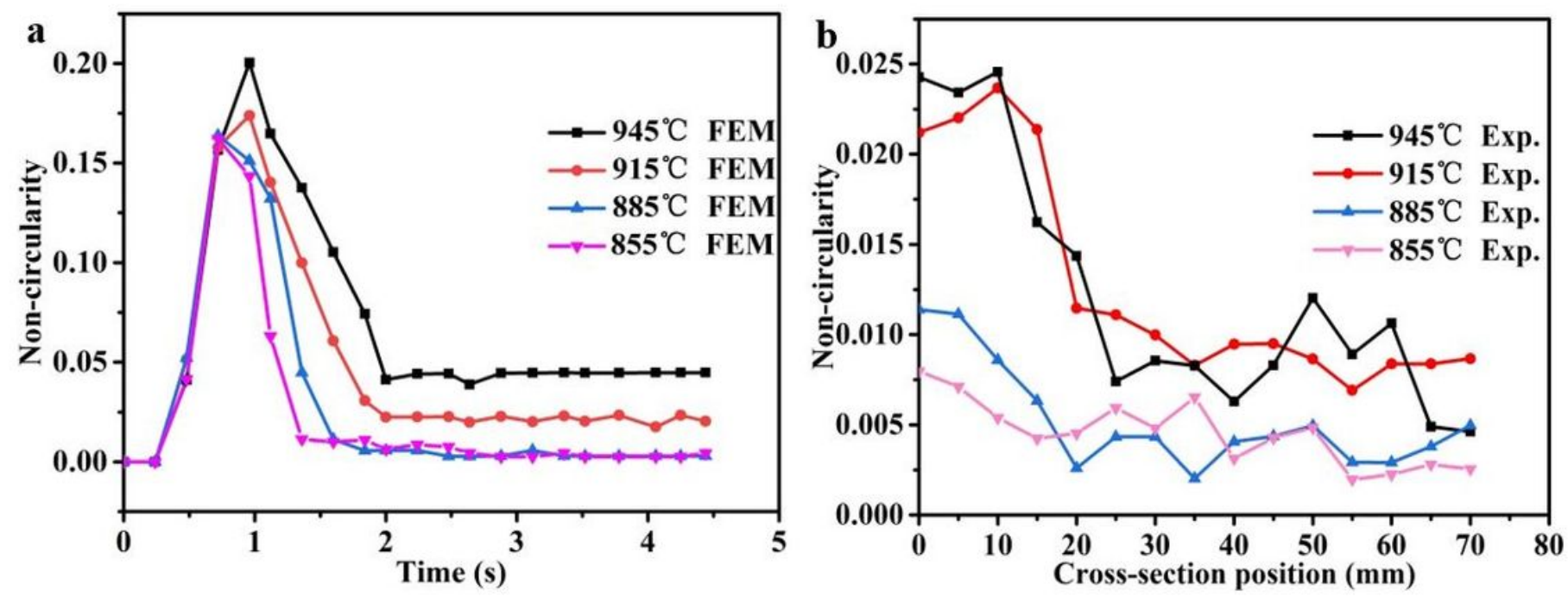

Figure 14

Non-circularity value of outer surface of parts at different IDT: a non-circularity results of symmetric section of FEM during rolling, $b$ non-circularity results of experiments at different axial position 

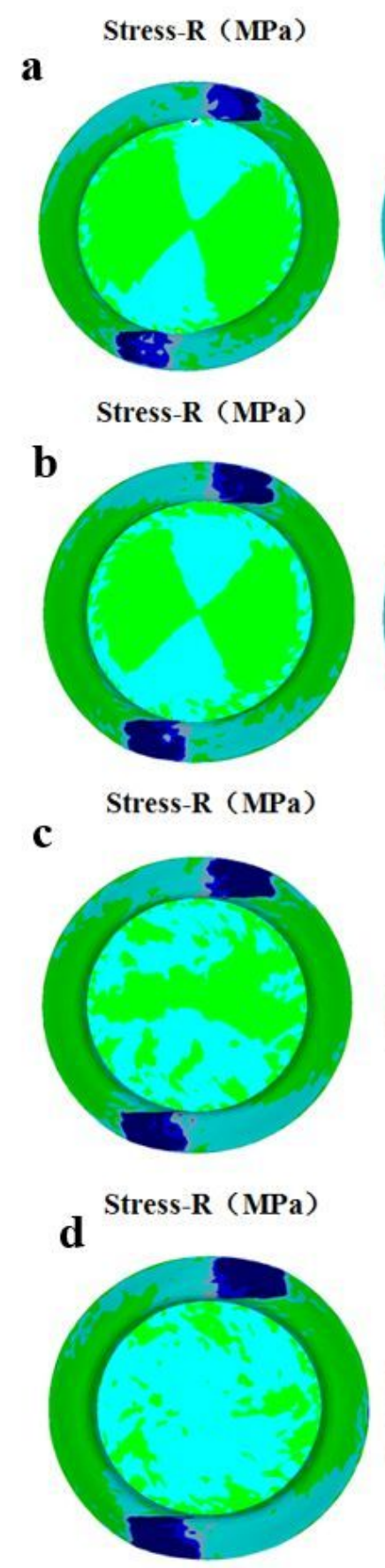

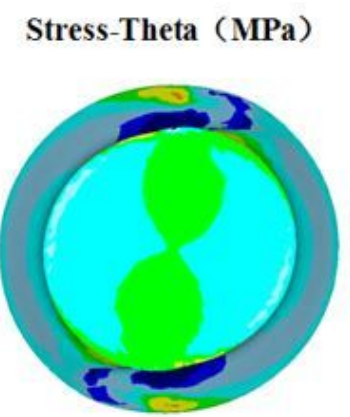

Stress-Theta (MPa)

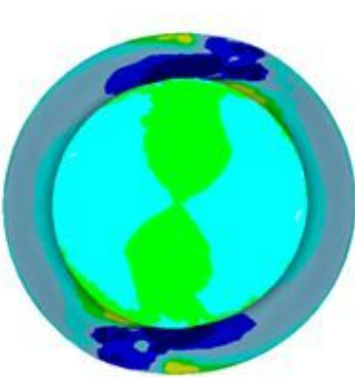

Stress-Theta (MPa)

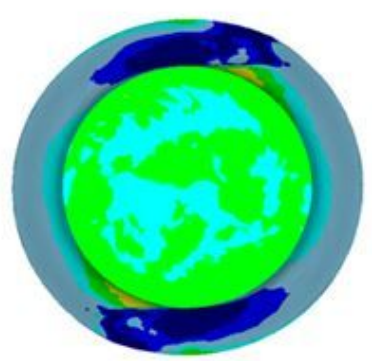

Stress-Theta (MPa)

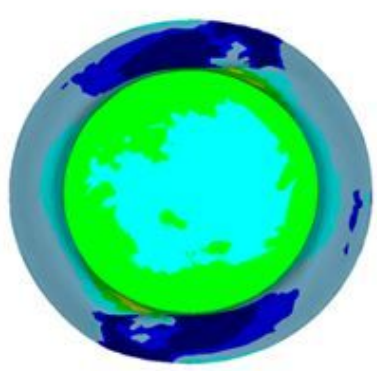

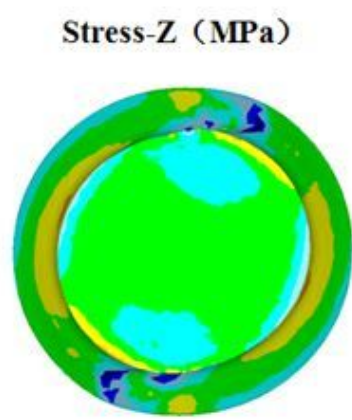

Stress-Z（MPa）

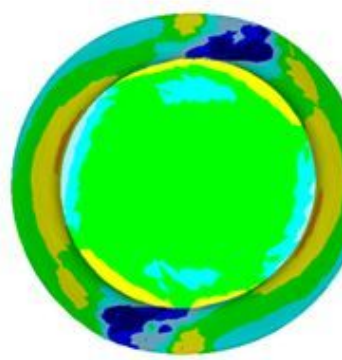

Stress-Z (MPa)

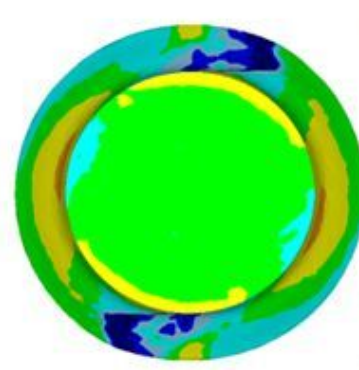

Stress-Z (MPa)

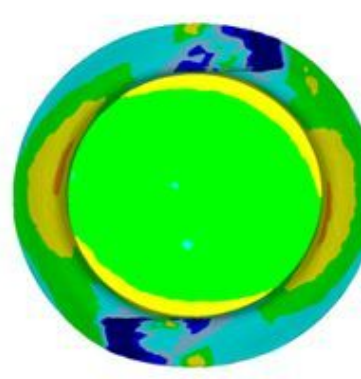

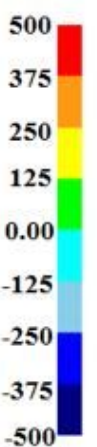

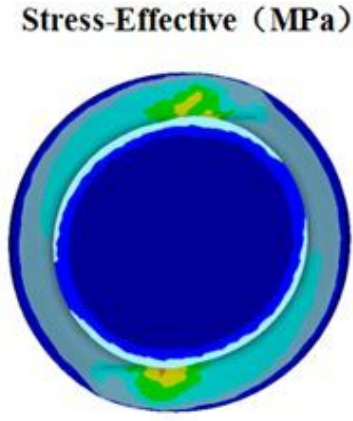

Stress-Effective (MPa)

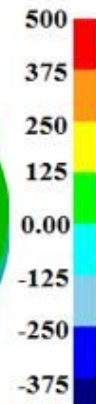

$-375$

.500

500

375

250

125
0.00
-125
-250
-375
$; 00$

$; 00$

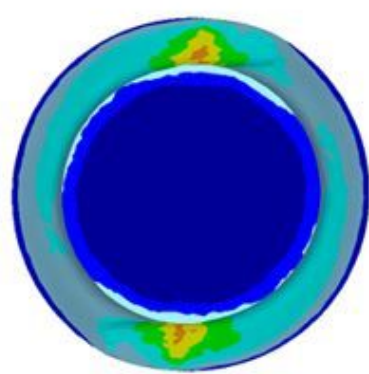

Stress-Effective (MPa) 0.00

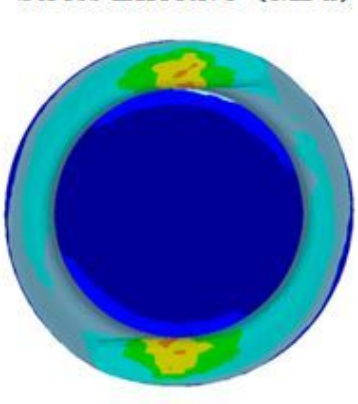

Stress-Effective (MPa)

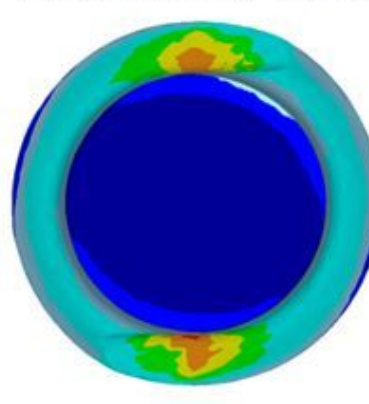
802
702
601
501
401
301
200
100
0.00 802 702 601 501 401 301 200 100 802 702 601 501 401 301 200 100 0.00 802 702 601 501 401 301 200 100 0.00

\section{Figure 15}

Stress distribution in the stretching zone: a $\mathrm{T}=945^{\circ} \mathrm{C}, \mathrm{b} \mathrm{T}=915^{\circ} \mathrm{C}, \mathrm{c} \mathrm{T}=885^{\circ} \mathrm{C}, \mathrm{d} \mathrm{T}=855^{\circ} \mathrm{C}$ 


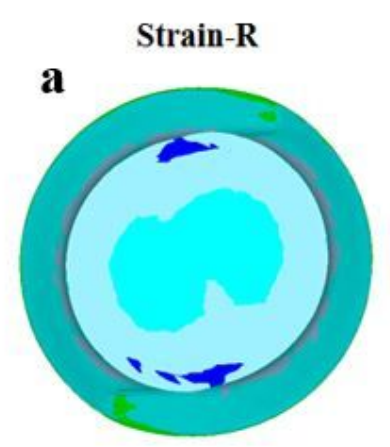

b Strain-R
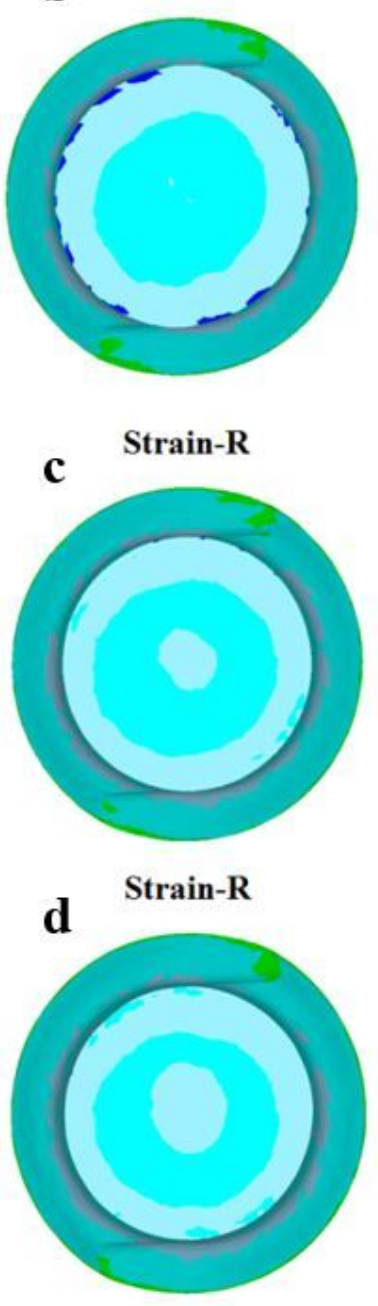
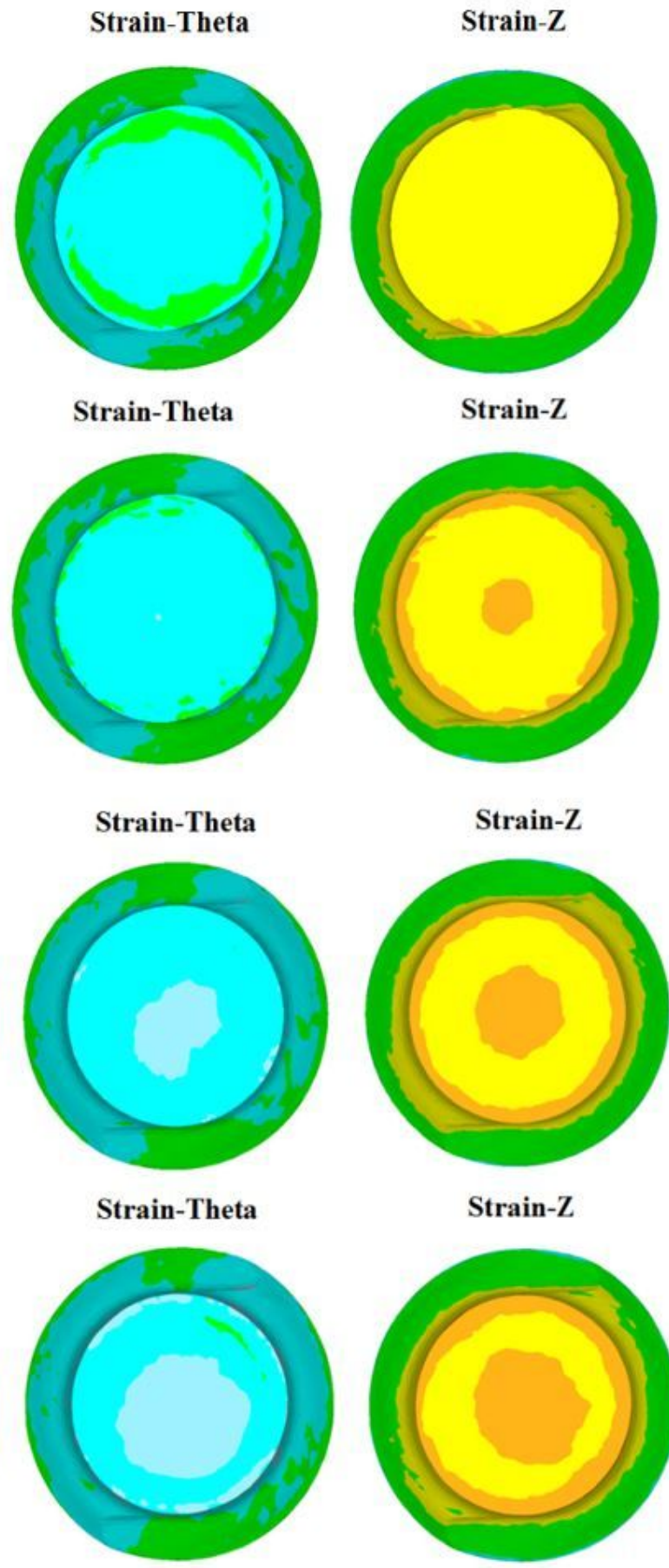

Strain-Z
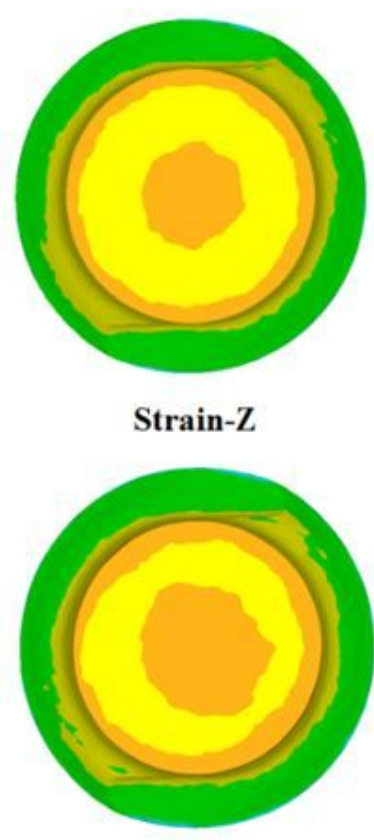
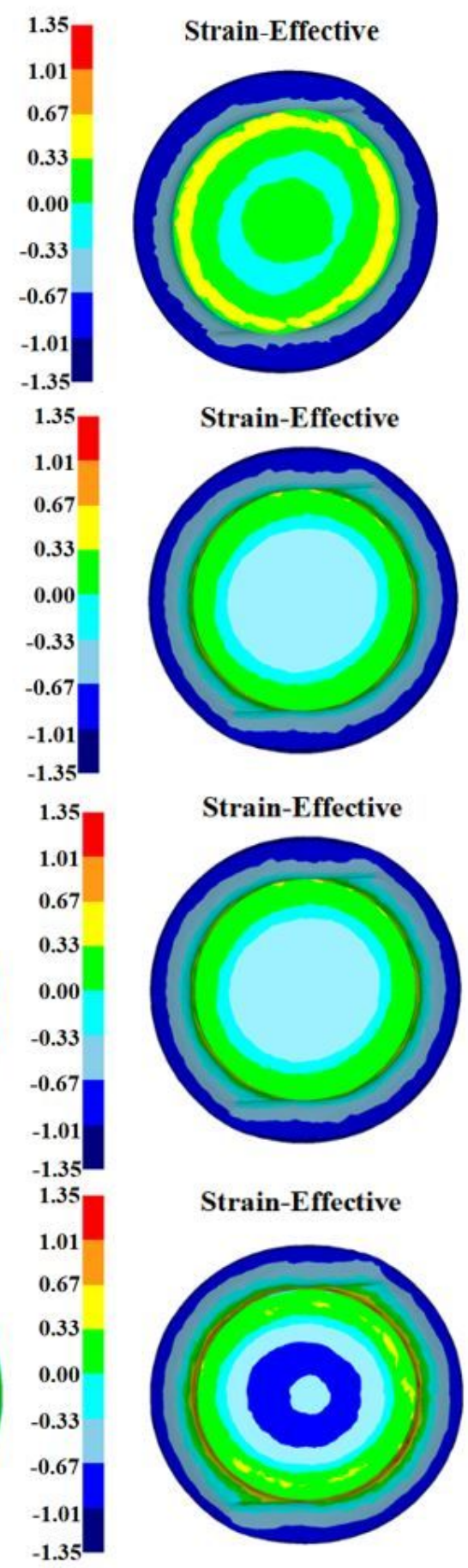

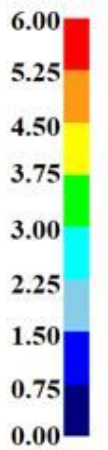

6.00

5.25
4.50
3.75
3.00
2.25
1.50
0.75
0.00

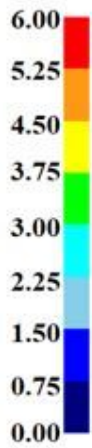

0.00

6.00
5.25
4.50
3.75
3.00
2.25
1.50
0.75
0.00

Figure 16

Strain distribution in the stretching zone: a $\mathrm{T}=945^{\circ} \mathrm{C}, \mathrm{b} \mathrm{T}=915^{\circ} \mathrm{C}, \mathrm{c} \mathrm{T}=885^{\circ} \mathrm{C}, \mathrm{d} \mathrm{T}=855^{\circ} \mathrm{C}$ 

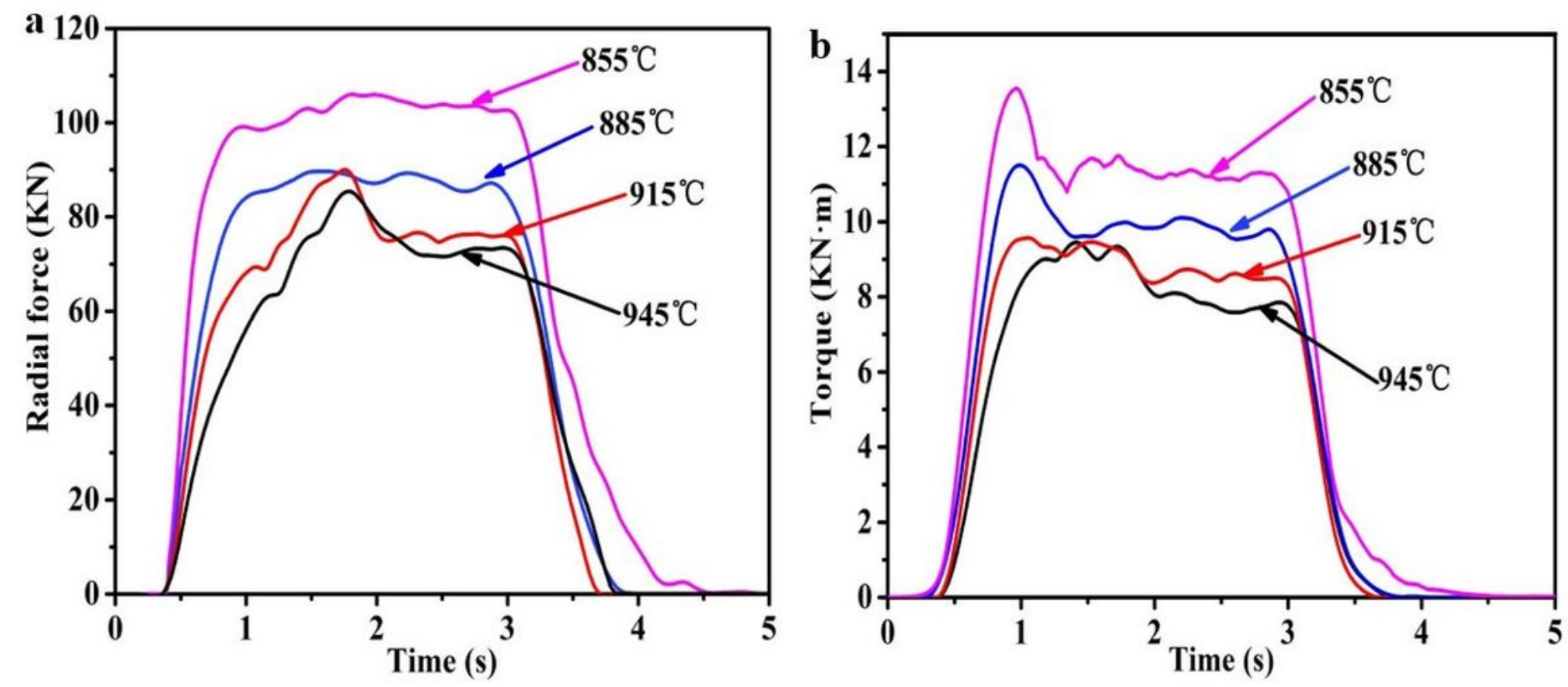

Figure 17

Effective of the IDTs on force and torque in CWR processes
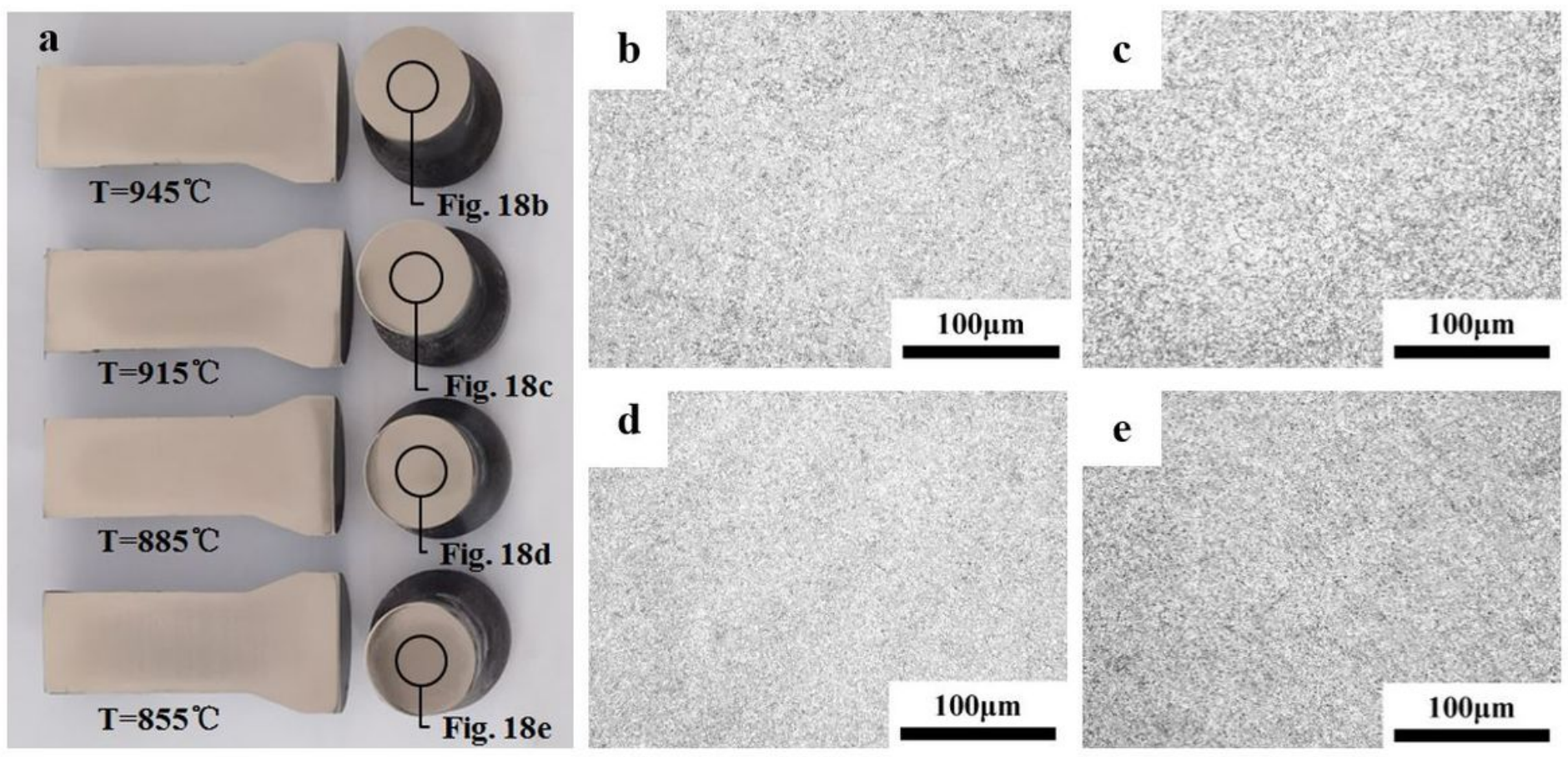

\section{Figure 18}

Internal quality of parts at different IDTs: a sectional display of different parts, b T=945 ${ }^{\circ} \mathrm{C}, \mathrm{c} \mathrm{T}=915^{\circ} \mathrm{C}, \mathrm{d}$ $\mathrm{T}=885^{\circ} \mathrm{C}, \mathrm{e} \mathrm{T}=855^{\circ} \mathrm{C}$ 


\section{Sample 1}

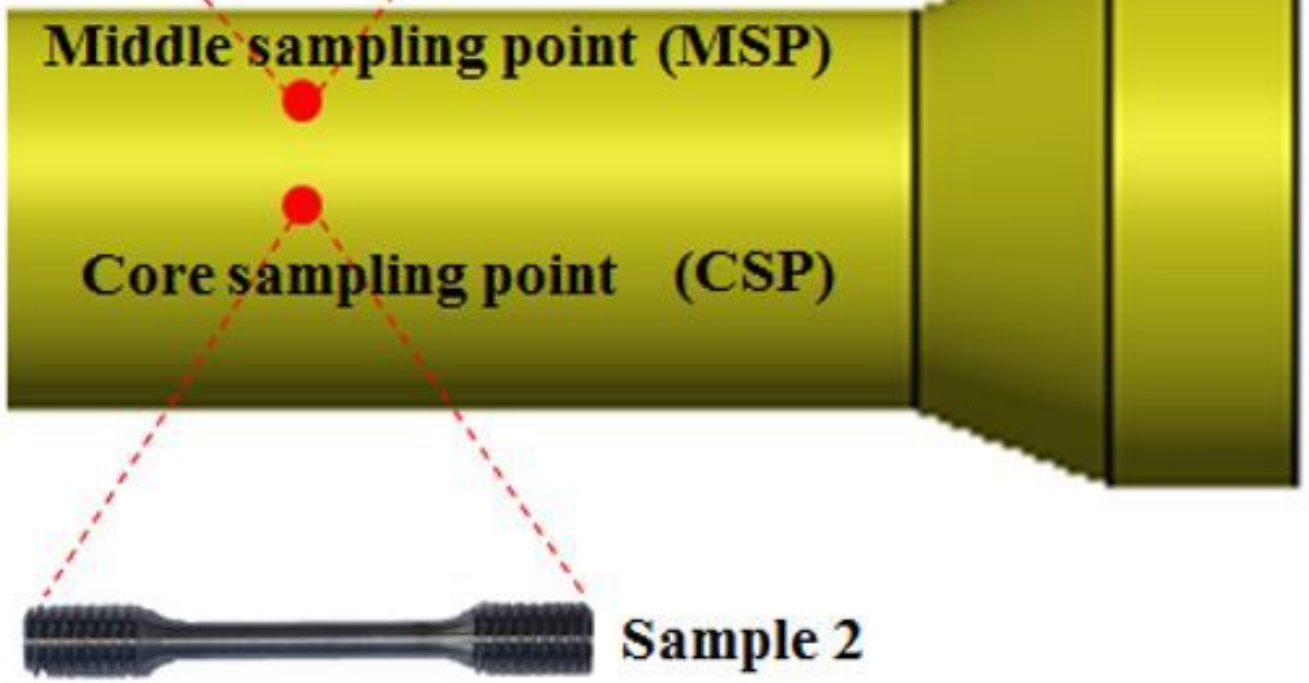

Figure 19

Mechanical properties and microstructure test sampling position distribution
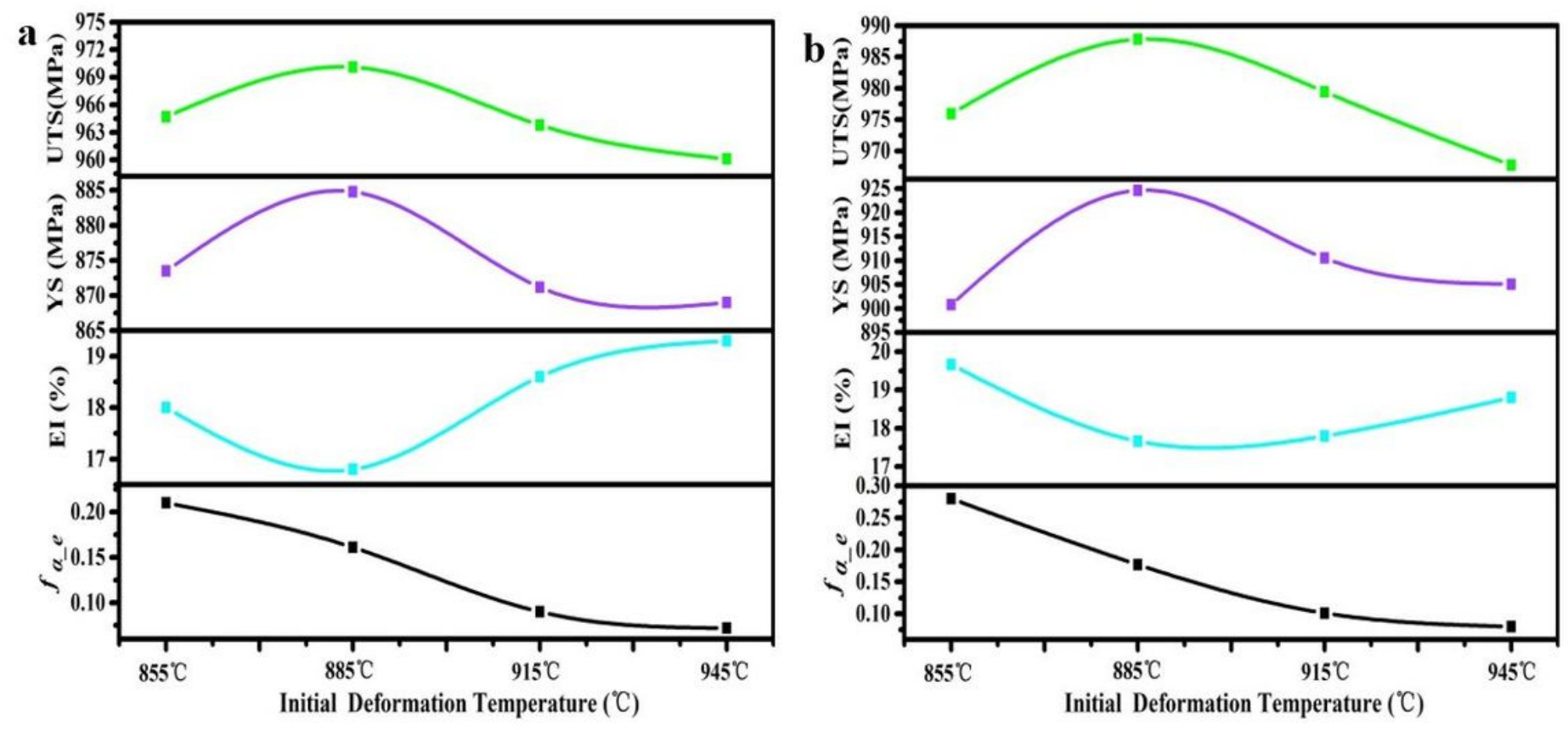

Figure 20 
Comparison of the mechanical properties at different IDTs of a CSP b MSP
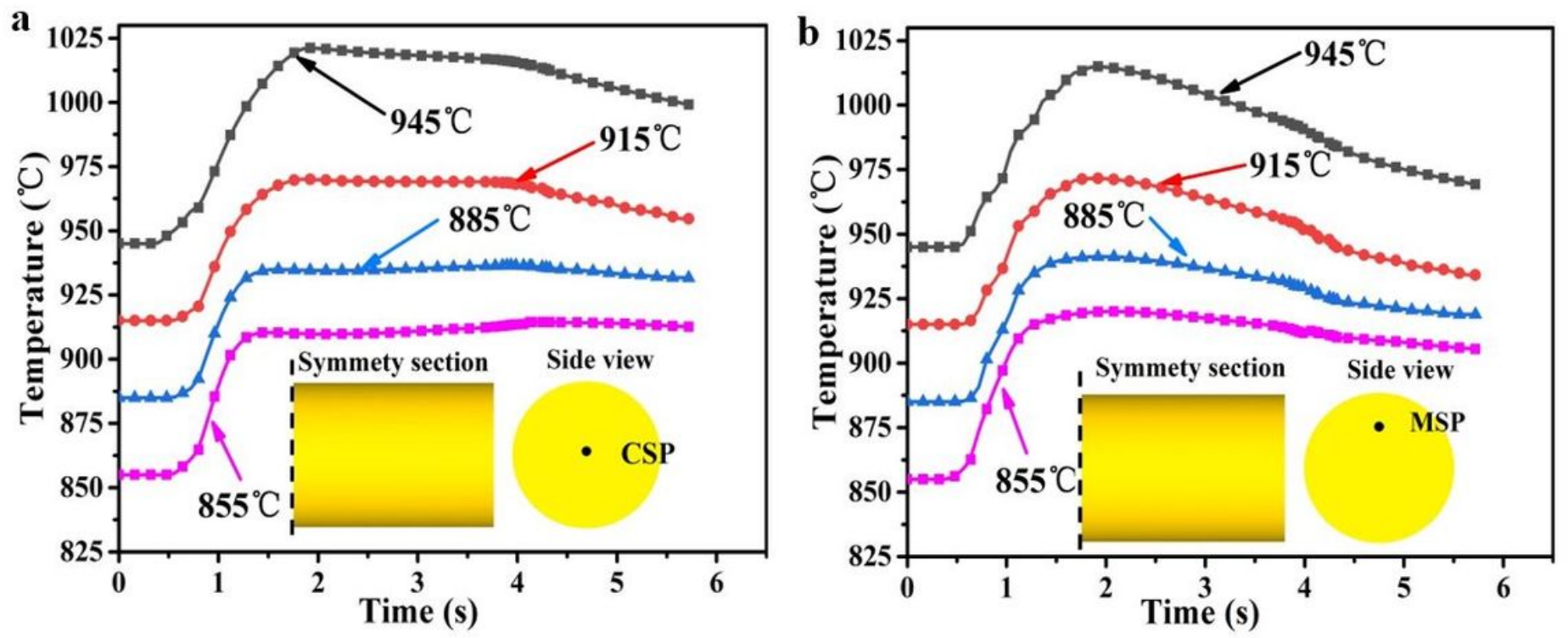

Figure 21

Temperature distribution of CWR forming TC4 alloy in symmetry sections: a CSP, b MSP 

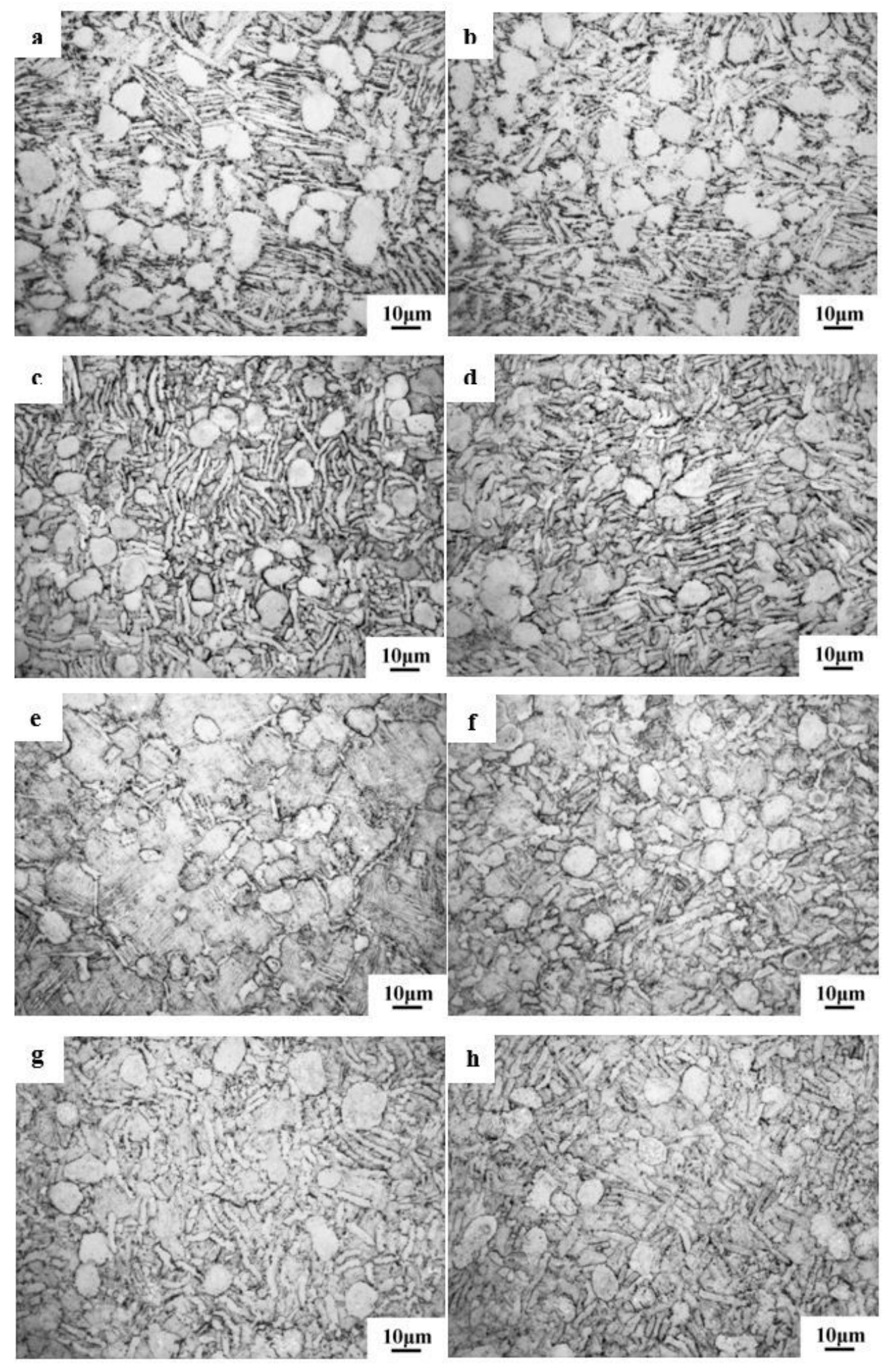

\section{Figure 22}

The microstructure of CSP and MSP of parts at different IDTs: a T $=855^{\circ} \mathrm{C}, \mathrm{CSP} ; \mathrm{b} \mathrm{T}=855^{\circ} \mathrm{C}, \mathrm{MSP}$; c $\mathrm{T}=885^{\circ} \mathrm{C}, \mathrm{CSP} ; \mathrm{d} \mathrm{T}=885^{\circ} \mathrm{C}, \mathrm{MSP} ;(\mathrm{e}) \mathrm{T}=915^{\circ} \mathrm{C}, \mathrm{CSP} ; \mathrm{f} \mathrm{T}=915^{\circ} \mathrm{C}, \mathrm{MSP} ; \mathrm{g} \mathrm{T}=945^{\circ} \mathrm{C}, \mathrm{CSP} ; \mathrm{h} \mathrm{T}=945^{\circ} \mathrm{C}, \mathrm{MSP}$ 